\title{
Modelos matemáticos y parámetros cinéticos relacionados con la producción de astaxantina en Haematococcus pluvialis
}

\author{
Mathematical Models and Kinetic Parameters Related to The Production of Astaxanthin in \\ Haematococcus Pluvialis
}

\begin{abstract}
Tatiana Torres Ospina ${ }^{a}$, Judith Elena Camacho Kurmen ${ }^{b}$
a Semillero de Investigación Bioprocesos y Control, Facultad de Ciencias de la Salud, Universidad Colegio Mayor de Cundinamarca, Colombia tatorres@unicolmayor.edu.co | https://orcid.org/0000-0002-8880-1501

b Grupo de Investigación Bioprocesos y Control, Facultad de Ciencias de la Salud, Universidad Colegio Mayor de Cundinamarca, Colombia jelenacamacho@unicolmayor.edu.co | https://orcid.org/0000-0002-9588-9935
\end{abstract}

Citation: Torres Ospina, T. y Camacho Kurmen, J. E. (2022). Modelos matemáticos y parámetros cinéticos relacionados con la producción de astaxantina en Haematococcus pluvialis. Mutis, 12(1). https://doi.org/10.21789/22561498.1743

Recibido: 26 de abril de 2021

Aceptado: 1 de julio de 2021

Copyright: () 2022 por los autores. Licenciado para Mutis. Este artículo es un artículo de acceso abierto distribuido bajo los términos y condiciones de la licencia Creative Commons Attribution (https:// https://creativecommons.org/licenses/bync-sa/4.0/).

\section{RESUMEN}

La microalga biflagelada unicelular de agua dulce Haematococcus pluvialis tiene una gran importancia industrial al ser considerada una fuente de producción natural de astaxantina, carotenoide utilizado como colorante y compuesto bioactivo. Este microorganismo es el principal productor de astaxantina de mejor calidad. La inducción de caroteno génesis se logra cuanto mayor es la exposición a condiciones de estrés, pues se genera así la mayor acumulación de astaxantina. Se ha observado también que, si las células están expuestas a un exceso de condiciones de estrés, el crecimiento celular cesa por completo y las células comienzan a morir en un tiempo relativamente corto, lo que dificulta su producción. El objetivo de esta revisión es conocer los modelos usados para describir la cinética de crecimiento de $H$. pluvialis y establecer los parámetros cinéticos que mejor expliquen el crecimiento de la microalga para emplearlos en el cultivo en laboratorio y su escalamiento en biorreactores o fotobiorreactores (FBR). Los modelos matemáticos más aplicados para el monitoreo del crecimiento de la microalga son el logístico, Baranyi-Roberts, exponencial y Monod. Se han propuesto modelos cinéticos de crecimiento teniendo en cuenta parámetros como la irradiancia y el color de luz. Los parámetros cinéticos usados son la velocidad máxima de crecimiento ( $\mu$ máx), el tiempo de duplicación (td), la biomasa inicial (Xo), la biomasa final (Xf) y la productividad del carotenoide (Yp/Ys), para establecer las condiciones óptimas de cultivo y producción del carotenoide, utilizando los coeficientes de correlación que genera el modelo, a fin de garantizar el cultivo de la microalga bajo las condiciones seleccionadas y validar los datos encontrados.

Palabras clave: carotenoide, fotobiorreactor, microalga, modelos matemáticos, parámetros cinéticos

\section{ABSTRACT}

The Haematococcus pluvialis, a freshwater unicellular biflagellate microalga, is of great importance industrially as it is considered a source of natural production of astaxanthin, a carotenoid used as a colorant and a bioactive compound. This microorganism is the main producer of the best quality astaxanthin. The induction of caro- 
tene genesis is achieved when exposure to stress conditions is greater, and this is how the greatest accumulation of astaxanthin is generated. It has also been observed that, if cells are exposed to excess stress conditions, cell growth ceases completely and cells begin to die in a relatively short time, which makes their production difficult. The objective of this review is to show the models used to describe the growth kinetics of $H$. pluvialis and to establish the kinetic parameters that best explain the growth of the microalgae for use in laboratory culture and its scaling up in bioreactors or photobioreactors (PBR). The most applied mathematical models for monitoring the growth of microalgae are logistic, Baranyi-Roberts, exponential, and Monod. Kinetic growth models have been proposed considering parameters such as irradiance and light color. The kinetic parameters used are the maximum growth speed ( $\mu$ max), the doubling time (td), the initial biomass (Xo), the final biomass (Xf) and the carotenoid productivity $(\mathrm{Yp} / \mathrm{Ys})$, to establish the optimal conditions for cultivating and producing the carotenoid, using the correlation coefficients generated by the model, in order to guarantee the cultivation of microalgae under the selected conditions and validate the data found.

Keywords: carotenoid, photobioreactor, microalgae, mathematical models, kinetic parameters

\section{INTRODUCCIÓN}

La microalga verde biflagelada unicelular de agua dulce Haematococcus pluvialis Flotow pertenece a la clase Chlorophyceae, orden Volvocales y familia Haematococcaseae. Tiene un tamaño celular de entre 8 y $50 \mathrm{Pm}$, que se caracteriza por presentar dos flagelos con los que se desplaza (Sánchez-Sendra, 2019). Su ciclo de vida consta de cuatro tipos de morfologías celulares distinguibles: macrozooides (zoosporas); microzooides y palmela, que forman parte de la denominada "fase vegetativa verde"; y, por último, hematocistos (aplanosporas), conocidos como "fase enquistada acumulada de astaxantina roja inmóvil", desde el momento en que cesa su crecimiento en la fase estacionaria, proceso de transformación en el que ocurre la acumulación del pigmento (Shah et al., 2016; Camacho et al., 2013, Ramírez, 2013). Los cambios de fase en el crecimiento de $H$. pluvialis están caracterizados por la pérdida de los flagelos y la formación de una matriz extracelular gelatinosa, siendo más grande y resistente la célula como aplanóspora (Sánchez-Sendra, 2019).

La astaxantina ( $3,3^{\prime}$-dihidroxi- $\beta, \beta$-caroteno-4, 4'-diona) pertenece a los carotenoides, pigmento secundario rojo brillante, de la misma familia que el licopeno, la luteína y el $\beta$-caroteno, y que se sintetiza de manera natural en microalgas, plantas, levaduras, bacterias y está presente en muchos mariscos, como el salmón, la trucha, el besugo, el camarón, la langosta y los huevos de pescado (Ramírez, 2013; Zhao et al., 2019). También es responsable del color de plumas en aves como flamencos, codornices y cigüeñas (Hu et al., 2018). Este carotenoide es ampliamente utilizado en la acuicultura, la nutrición, la industria farmacéutica, la nutracéutica y la cosmética debido a su característica como pigmento y como compuesto bioactivo como antioxidante, en la actividad antiinflamatoria, antitumoral, antiangiogénica, y por sus propiedades cardioprotectoras y hepatoprotectoras (Hu et al., 2018; Wang et al., 2019; Zhao et al., 2019; Gajardo et al., 2011; Montiel, 2020). 
La astaxantina es absorbida junto con los ácidos grasos mediante difusión pasiva; su capacidad antioxidante, al ser comparada con el $\beta$-caroteno y la vitamina $E$, es superada por 38-veces y 500-veces, respectivamente (Zhang et al., 2017). Su estructura facilita su capacidad antioxidante al transportase a los tejidos corporales, proteger las células y las membranas a base de lípidos del daño oxidativo, y por su propiedad de captación de radicales libres, protección mitocondrial, efectos antiinflamatorios y protección contra la glicación (Khandual et al., 2019).

Debido a la importancia de la astaxantina, el alga unicelular de agua dulce $H$. pluvialis ha adquirido gran relevancia a nivel industrial (Gajardo et al., 2011; Camacho et al., 2013; Ramírez, 2013), al ser considerada una gran fuente de producción natural de astaxantina, ya que es capaz de acumular hasta un $3 \%$ de este carotenoide en peso seco (Córdoba et al., 2015). De hecho, sintetizan considerablemente más que otros microrganismos productores de astaxantina como Phaffa rhodozyma y Chlorella zofingiensis (Zhao et al., 2019). Sin embargo, la microalga presenta problemas con su cultivo, al tener un crecimiento vegetativo lento y bajo aun en condiciones de cultivo favorables, además del deterioro o muerte celular en condiciones de estrés como luz, falta de nitrógeno, concentración de sal y estrés nutricional; en consecuencia, se ve afectada la acumulación de astaxantina (Ramírez, 2013).

La inducción de caroteno génesis es mayor con la exposición a condiciones de estrés, al ocasionar una mayor acumulación de astaxantina; en algunos casos, si las células están expuestas a un alto estrés, el crecimiento celular cesa por completo y las células comienzan a morir en un tiempo relativamente corto, lo que dificulta su producción principalmente a gran escala (Ramírez, 2013). Por lo tanto, se han reportado estudios donde se evalúa el efecto de diferentes factores sobre la acumulación de este metabolito secundario (astaxantina), con el fin de aumentar su síntesis y producción, como en la investigación de de Miranda et al. (2019), donde se han utilizado factores como la concentración de nitrato $\left(\mathrm{NaNO}_{3}\right)$, la cual en condiciones óptimas, para la obtención de astaxantina y evitar el cese de la división celular, debe de ser de $0.15 \mathrm{~g} / \mathrm{L}$; otro factor es la intensidad lumínica, reportada con $500 \mu \mathrm{mol} / \mathrm{m}^{2} \mathrm{~s}$, logrando una gran concentración de astaxantina ( $26 \mathrm{mg} / \mathrm{L})$; asimismo, la influencia de la temperatura a $30{ }^{\circ} \mathrm{C}$ inhibe la división celular e induce la síntesis de astaxantina, aumentando así el contenido de 10 a 15 veces en comparación con el cultivo a condiciones óptimas, como lo han reportado Shah et al. (2016).

La luz y el nitrógeno son los dos factores más efectivos que influyen en el crecimiento y síntesis de astaxantina en este organismo, principalmente porque ambos requisitos para el crecimiento son diferentes de aquel para la síntesis de astaxantina (Wang et al., 2013). Por lo anterior, los cultivos adoptan habitualmente una estrategia de dos pasos: el primero consiste en promover el crecimiento de algas en condiciones favorables de cultivo (por ejemplo, poca luz y repletas de nitrógeno); cuando se alcanza una densidad celular alta, pero optimizada, el cultivo entra en el segundo paso donde la microalga se somete a condiciones de estrés (por ejemplo, alta irradiancia y deficiencia de nitrógeno) para la producción de astaxantina (Wang et al., 2013). Hernández et al. (2015) destacan el factor de la luz como el más importante, incluyendo el diseño adecuado de un fotobiorreactor que, combinado con las condiciones óptimas, permite mejorar las características de cultivo y la producción de astaxantina. 
Otros tipos de estrés que inducen a la acumulación de astaxantina son temperatura, intensidad lumínica, ciclos de luz/oscuridad, concentración de nutrientes, $\mathrm{pH}$, especies reactivas de oxígeno, sales y presencia de inhibidores de procesos metabólicos a diferente nivel (Camacho et al., 2013; Shah et al., 2016). De la misma manera, métodos como la estimulación mediante el sonido audible a las microalgas en estado vegetativo han mostrado resultados prometedores para mejorar la tasa de crecimiento en microalgas de $\mathrm{H}$. pluvialis, proceso en el que se sometieron a sonido audible durante $8 \mathrm{~h}$ en 22 días de cultivo, con títulos de Blues for Elle y Far and Wide, evidenciándose una tasa de crecimiento más alta ( 0.03 por día) y un $58 \%$ más alto, en comparación con el cultivo que no tiene sonido audible (Christwardana y Hadiyanto, 2017).

Ramírez (2013) evalúa el potencial que tiene $H$. pluvialis para la producción industrial de astaxantina. Así, estudió el efecto del porcentaje de dióxido de carbono en la aireación, de la intensidad de luz y de la concentración de nitrógeno y de fósforo en el crecimiento y la producción de astaxantina en un fotobiorreactor tipo airlift a partir de esta microalga. Cobraron importancia parámetros como la intensidad de luz y la concentración de fósforo, con un efecto positivo en el crecimiento de la microalga, mientras que el porcentaje de $\mathrm{CO}_{2}$ presentó un efecto negativo; la concentración de nitrógeno no tuvo efecto significativo en la velocidad específica de crecimiento. El precio de mercado de la astaxantina sintética es de alrededor de $\$ 2500 / \mathrm{kg}$, la cual contiene diferentes isómeros del producto natural que causan preocupación por la seguridad de los consumidores (Onorato y Rösch, 2020), y requiere además de un alto costo para su producción y tiene menor capacidad antioxidante comparada con la natural (Ramírez, 2013). Por ello, la astaxantina natural es un producto preferido de elección.

Por estas razones, el objetivo de este artículo es conocer los modelos de crecimiento que mejor expliquen el proceso de la microalga $H$. pluvialis, como lo son los propuestos por Baranyi-Roberts, Gompertz, logístico y Monod. Para ello, se definirán los parámetros cinéticos relacionados como la velocidad de crecimiento, el tiempo de duplicación, la productividad de biomasa y la productividad de pigmentos como la astaxantina, bajo condiciones de laboratorio y en su producción a gran escala, en función de establecer las condiciones óptimas para el cultivo de la microalga y producción del carotenoide, y relacionarlas con los factores de estrés utilizados. Los datos fueron analizados usando Excel 2013 con diferentes variables por analizar, incluyendo año de publicación, idioma, temas de estudio y enfoque del estudio. Finalmente, se acudió a estadística descriptiva para analizar los resultados. Los indicadores bibliométricos analizados y utilizados fueron citación, contenido y metodología (figuras 1, 2 y 3). 
Figura 1. Relación de publicaciones revisadas por año de publicación

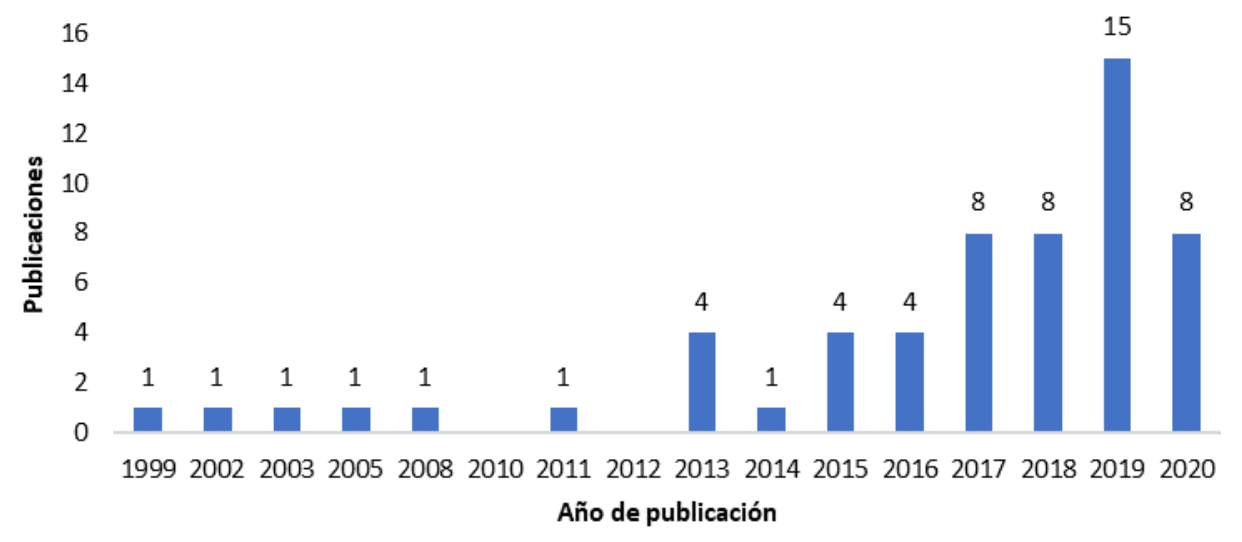

Fuente: elaboración propia.

Figura 2. Contenido y metodología

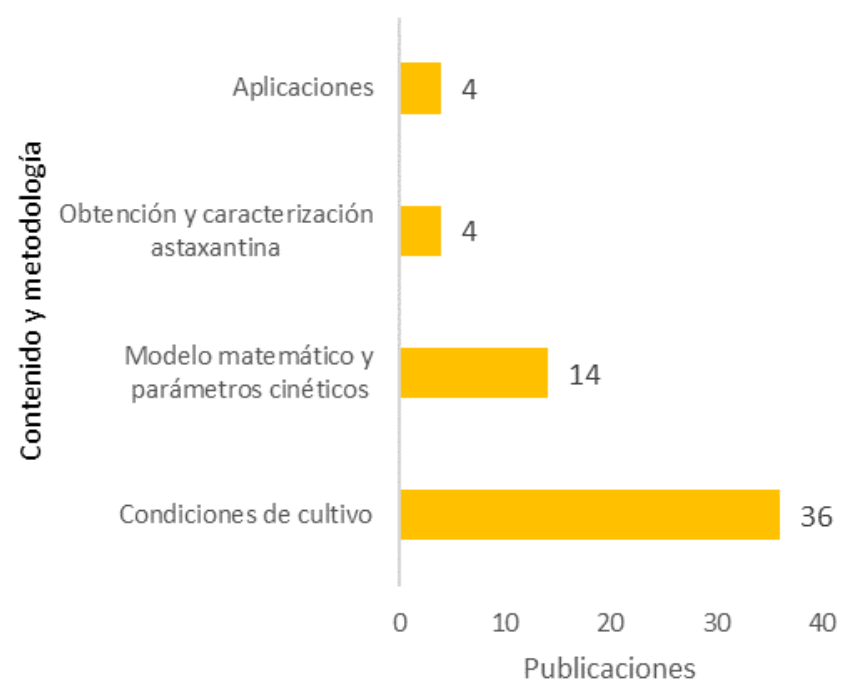

Fuente: elaboración propia. 
Figura 3. Idioma de las publicaciones revisadas

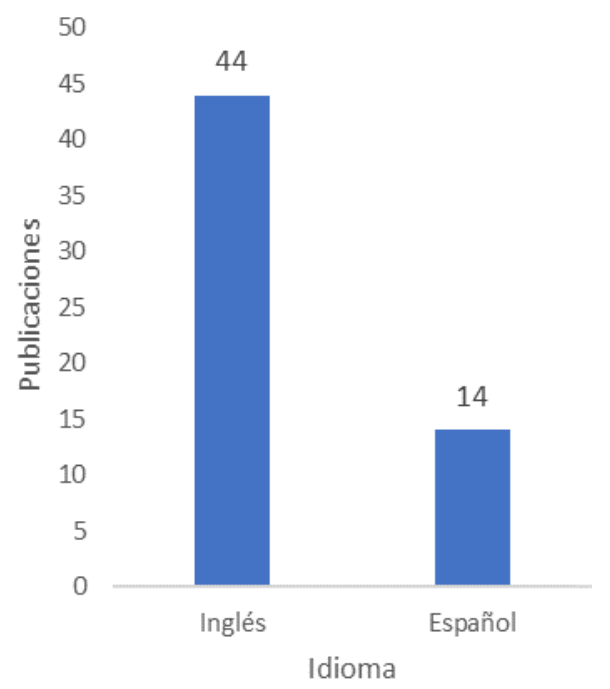

Fuente: elaboración propia.

Respecto al indicador de colaboración, en los 52 artículos revisados, 204 autores fueron relacionados. Para el caso del indicador de citación, el artículo de Shah et al. (2016) presenta la mayor citación, con un valor de 419. Se encontró en los artículos revisados que solo un 5,7\% no presentaban todavía citación.

\section{Condiciones de estrés ambiental en cultivos de $H_{\text {. pluvialis }}$}

En la tabla 1 se presentan las condiciones de estrés utilizadas para el cultivo de la microalga relacionadas con la producción de astaxantina en $H$. pluvialis. Se reportan allí la productividad de biomasa y del pigmento astaxantina, así como los parámetros cinéticos fundamentales para la selección de las condiciones óptimas del cultivo de la microalga. Ciertamente, modelar el crecimiento de microorganismos es importante para entender el comportamiento de los organismos bajo diferentes condiciones ambientales, tales como temperatura, intensidad de luz, $\mathrm{pH}$ y nutrientes (Çelekli et al., 2008). Por esto, el uso de un modelo cinético es esencial para optimizar las condiciones de cultivo de la microalga y la producción de astaxantina, lo cual es el interés de este estudio. Los modelos matemáticos que tienen la capacidad de predecir la dinámica de los cultivos de microalgas en diferentes condiciones de crecimiento, como luz, concentración de nitrógeno o concentración de fósforo, ayudarán a optimizar el rendimiento del proceso, las condiciones de funcionamiento y los sistemas de cultivo de escalado para la tecnología comercial basada en microalgas. 
Torres Ospina, T. y Camacho Kurmen, J. E. (2022). https://doi.org/10.21789/22561498.1743

Tabla 1. Condiciones de estrés en cultivos de $H$. pluvialis relacionados con concentración de astaxantina

\begin{tabular}{|c|c|c|c|c|c|c|c|}
\hline $\begin{array}{c}\text { Medio de } \\
\text { cultivo } \\
\text { pH } \\
\text { Temperatura }\end{array}$ & $\begin{array}{l}\text { Luz } \\
\text { Color de luz } \\
\text { Irradiancia }\end{array}$ & $\begin{array}{c}\text { Biomasa } \\
\text { inicial/ } \\
\text { Biomasa } \\
\text { final }\end{array}$ & Fotoperiodo & $\begin{array}{l}\text { Condiciones } \\
\text { de estrés }\end{array}$ & $\begin{array}{c}\text { Tiempo de } \\
\text { estudio }\end{array}$ & $\begin{array}{l}\text { Cantidad de } \\
\text { astaxantina }\end{array}$ & Bibliografía \\
\hline $\begin{array}{l}\text { M1-F1-Basal- } \\
\text { G11-BBM } \\
24( \pm 2)^{\circ} \mathrm{C}\end{array}$ & $\begin{array}{l}\text { Luz blanca } \\
\text { artificial fluores- } \\
\text { cente, lluminancia } \\
55000 \text { ( } \pm 50 \text { Lux) }\end{array}$ & $\begin{array}{l}4 \times 10^{4} \\
\text { cel./mL }\end{array}$ & $18: 06 \mathrm{~h}$ & $\mathrm{NaCl}(0.025 \%)$ & 9 días & $\begin{array}{c}\text { 3,484 } \mathrm{mg} \mathrm{L}^{-1} \\
\text { día }{ }^{-1}\end{array}$ & $\begin{array}{c}\text { Ramírez } \\
\text { (2013) }\end{array}$ \\
\hline 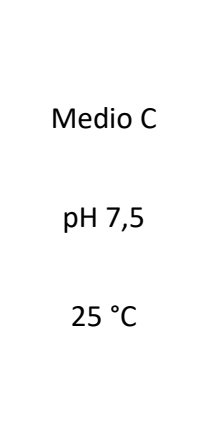 & $\begin{array}{l}\text { Luz artificial } \\
\text { fluorescente } \\
10 \mu \mathrm{mol} \mathrm{m}{ }^{-2} \mathrm{~s}^{-1}\end{array}$ & $\begin{array}{l}4 \times 10^{4} \\
\text { cel. } / \mathrm{mL}\end{array}$ & N. A. & $\begin{array}{c}\text { Acetato de } \\
\text { sodio } 1,6 \mathrm{~g} / \mathrm{L} \\
2 \mathrm{mM} \text { de } \\
\text { Nitrato de } \\
\text { sodio } \\
\text { Luz } 400 \mu \mathrm{mol} \\
\mathrm{m}^{-2} \mathrm{~s}^{-1}\end{array}$ & 14 días & $2.5 \mathrm{mg} \mathrm{L}^{-1}$ día & $\begin{array}{c}\text { Zhang } \\
\text { et al. (2017) }\end{array}$ \\
\hline $\begin{array}{c}\text { MES-Volvox } \\
25^{\circ} \mathrm{C}\end{array}$ & $\begin{array}{l}\text { Blanco frío, bombi- } \\
\text { Ilas fluorescentes } \\
80 \mu \mathrm{mol} \mathrm{m-2} \mathrm{s}^{-1}\end{array}$ & $\begin{array}{l}1 \times 10^{6} \\
\text { cel./mL }\end{array}$ & N. A. & $\begin{array}{c}\mathrm{CO}_{2}(15 \%), \\
\text { Alta } \\
\text { luminosidad } \\
\left(300 \mu \mathrm{mol} \mathrm{m} \mathrm{m}^{-2}\right. \\
\left.\mathrm{s}^{-1}\right) .\end{array}$ & 13 días & $36 \mathrm{mg} / \mathrm{g}$ & $\begin{array}{c}\text { Zhanga } \\
\text { et al. (2018) }\end{array}$ \\
\hline $\begin{array}{l}\text { RM-OHM-BBM- } \\
\text { MES Volox } \\
\text { pH } 6.7 \\
25^{\circ} \mathrm{C}\end{array}$ & $\begin{array}{c}70 \mu \mathrm{E} / \mathrm{m}^{2} \mathrm{~s} \\
\text { microestein de } \\
\text { irradiancia con } \\
\text { lámparas de luz } \\
\text { fluorescentes } \\
\text { blanca }\end{array}$ & $\begin{array}{l}1 \times 10^{4} \\
\text { cel./mL } \\
1,6 \times 10^{5} \\
\text { cel. } / \mathrm{mL}\end{array}$ & $18: 06 \mathrm{~h}$ & $\mathrm{CO}_{2}(5 \%)$ & 36 días & $8.3 \mu \mathrm{g} / \mathrm{mL}$ & $\begin{array}{l}\text { Niño } \\
\text { et al. (2017) }\end{array}$ \\
\hline
\end{tabular}


Torres Ospina, T. y Camacho Kurmen, J. E. (2022). https://doi.org/10.21789/22561498.1743

\begin{tabular}{|c|c|c|c|c|c|c|c|}
\hline $\begin{array}{c}\text { Medio de } \\
\text { cultivo } \\
\text { pH } \\
\text { Temperatura }\end{array}$ & $\begin{array}{c}\text { Luz } \\
\text { Color de luz } \\
\text { Irradiancia }\end{array}$ & $\begin{array}{c}\text { Biomasa } \\
\text { inicial/ } \\
\text { Biomasa } \\
\text { final }\end{array}$ & Fotoperiodo & $\begin{array}{l}\text { Condiciones } \\
\text { de estrés }\end{array}$ & $\begin{array}{c}\text { Tiempo de } \\
\text { estudio }\end{array}$ & $\begin{array}{l}\text { Cantidad de } \\
\text { astaxantina }\end{array}$ & Bibliografía \\
\hline $\begin{array}{c}\mathrm{RM} \\
\mathrm{pH} \mathrm{6,7} \\
25^{\circ} \mathrm{C}\end{array}$ & $\begin{array}{l}\text { Lámparas fluores- } \\
\text { centes blancas } \\
\text { Irradiancia alta de } \\
\qquad 140 \mu \mathrm{E} \mathrm{m}^{-2} \mathrm{~s}^{-1}\end{array}$ & $\begin{array}{c}1 \times 10^{4} \\
\text { cel. } / \mathrm{mL} / \\
2.10 \times 10^{6} \\
\text { cel./ } \mathrm{mL}\end{array}$ & $20: 04 \mathrm{~h}$ & $\begin{array}{l}\text { Deficiencia de } \\
\text { Nitrogeno } \\
(4 \%) \\
\mathrm{CO}_{2}(5 \%)\end{array}$ & 36 días & $\begin{array}{c}3,52 \times 10^{-6} \mu \mathrm{g} \\
\text { cel- }{ }^{-1} \times \mathrm{mL}^{-1}\end{array}$ & $\begin{array}{c}\text { Gómez } \\
\text { et al. (2019) }\end{array}$ \\
\hline $\begin{array}{l}\text { Medio basal } \\
\text { pH 8,0 } \\
20^{\circ} \mathrm{C}\end{array}$ & $\begin{array}{c}\text { Lámparas } \\
\text { fluorescentes } \\
\text { blancas } \\
20 \mu \mathrm{E} / \mathrm{m}^{2} \mathrm{~s}\end{array}$ & $\begin{array}{l}4 \times 10^{5} \\
\text { cel./ mL }\end{array}$ & $12: 12 \mathrm{~h}$ & $\begin{array}{c}22.5 \mathrm{mM} \text { de } \\
\text { acetato }\end{array}$ & 4 días & 11 mg/g cel. & $\begin{array}{c}\mathrm{Hu} \\
\text { et al. (2018). }\end{array}$ \\
\hline $\begin{array}{c}\text { Medio BBM } \\
\text { modificado y } \\
\text { BG-11 modifica- } \\
\text { do } \\
25 \pm 1^{\circ} \mathrm{C}\end{array}$ & $\begin{array}{l}\text { Luz blanca fría } \\
150 \mu \mathrm{mol} / \mathrm{m}^{2} / \mathrm{s}\end{array}$ & $20 \mathrm{~g} / \mathrm{L}$ & N. A. & $\begin{array}{c}\mathrm{N}_{2} \text {, nitrato de } \\
\text { sodio, bicar- } \\
\text { bonato de } \\
\text { amonio o úrea } \\
(18 \mathrm{mM}), 300 \\
\mu \mathrm{mol} / \mathrm{m}^{2} / \mathrm{s} \\
\mathrm{CO}_{2} 1 \%\end{array}$ & 15 días más & $18,1 \mathrm{mg} / \mathrm{L} \mathrm{d}$ & $\begin{array}{c}\text { Wang et al. } \\
\text { (2019) }\end{array}$ \\
\hline $\begin{array}{c}\text { Medio basal de } \\
\text { Bold (BBM) } \\
\text { pH } 7.5 \\
25^{\circ} \mathrm{C}\end{array}$ & $\begin{array}{l}\text { Luz blanca } \\
\text { fluorescente } \\
60 \mu \mathrm{mol} \mathrm{m}{ }^{-2} \mathrm{~s}^{-1}\end{array}$ & $\begin{array}{l}3 \times 10^{5} / \\
\text { cel. } / \mathrm{mL}\end{array}$ & $12: 12 \mathrm{~h}$ & $\begin{array}{c}\mathrm{NaNO}_{3} \\
(8.32 \mathrm{mM})\end{array}$ & 6 días & $\begin{array}{c}975,65 \mathrm{mg} \\
1 \mathrm{DW}\end{array}$ & $\begin{array}{c}\text { Galarza } \\
\text { et al. (2019) }\end{array}$ \\
\hline $\begin{array}{c}\text { Medio OHM } \\
25^{\circ} \mathrm{C}\end{array}$ & $\begin{array}{l}\text { Luz blanca fluores- } \\
\text { cente } \\
50 \mu \mathrm{mol}-\mathrm{m}^{-2} \mathrm{~s}^{-1}\end{array}$ & $\begin{array}{l}5 \times 10^{5} \\
\text { cel. } / \mathrm{mL}\end{array}$ & N. A. & $\begin{array}{c}\text { Mecánico } \\
\text { (chip) }\end{array}$ & 7 días & N/A & $\begin{array}{c}\text { Park } \\
\text { et al. (2020) }\end{array}$ \\
\hline $\begin{array}{c}\text { Medio BBM } \\
\text { modificado con }\end{array}$ & $\begin{array}{l}\text { Luz led blanca fría } \\
\text { Intensidad de luz }\end{array}$ & N. A. & $12: 12 \mathrm{~h}$ & $\begin{array}{l}\text { Iluminación } \\
\text { continua de }\end{array}$ & 42 días & $27.0 \pm 1.9 \mathrm{mg} / \mathrm{L}$ & $\begin{array}{l}\text { Liyanaaachchi } \\
\text { et al. (2020) }\end{array}$ \\
\hline
\end{tabular}


Torres Ospina, T. y Camacho Kurmen, J. E. (2022). https://doi.org/10.21789/22561498.1743

\begin{tabular}{|c|c|c|c|c|c|c|c|}
\hline $\begin{array}{c}\text { Medio de } \\
\text { cultivo } \\
\text { pH } \\
\text { Temperatura }\end{array}$ & $\begin{array}{c}\text { Luz } \\
\text { Color de luz } \\
\text { Irradiancia }\end{array}$ & $\begin{array}{c}\text { Biomasa } \\
\text { inicial/ } \\
\text { Biomasa } \\
\text { final }\end{array}$ & Fotoperiodo & $\begin{array}{l}\text { Condiciones } \\
\text { de estrés }\end{array}$ & $\begin{array}{c}\text { Tiempo de } \\
\text { estudio }\end{array}$ & $\begin{array}{l}\text { Cantidad de } \\
\text { astaxantina }\end{array}$ & Bibliografía \\
\hline $\begin{array}{l}\text { fosfato } \\
30 \pm 2{ }^{\circ} \mathrm{C}\end{array}$ & $\begin{array}{c}\text { incidente de } 2000 \\
\text { LUX / } 14 \text { días }\end{array}$ & & & $\begin{array}{l}5000 \text { LUX } \\
41 \mathrm{mg} / \mathrm{L} \text { de } \\
\text { fosfato }\end{array}$ & & & \\
\hline $\begin{array}{l}\text { BG11 modifica- } \\
\text { do } \\
\text { pH 7.5-8.5 }\end{array}$ & $\begin{array}{l}\text { Luz alta }(300 \mu \mathrm{mol} \\
\left.\mathrm{m}^{-2} \mathrm{~s}^{-1}\right) \text { y luz baja } \\
\left(150 \mu \mathrm{mol} \mathrm{m}^{-2} \mathrm{~s}^{-1}\right)\end{array}$ & N. A. & N. A. & $\begin{array}{c}\text { Acetato de } \\
\text { sodio y ácido } \\
\text { acético } 2,2 \\
\text { mM } 1 \text { vez cada } \\
24 \text { h, hasta } \\
\text { 13,2 mM. } 2.2 \\
\text { mM } \\
\left(\mathrm{CH}_{3} \mathrm{COOH}\right)\end{array}$ & 14 días & $\begin{array}{c}140 \mathrm{mg} \\
\mathrm{m}^{-2} \mathrm{day}^{-1}\end{array}$ & $\begin{array}{c}\text { Wen } \\
\text { et al. (2020) }\end{array}$ \\
\hline $\begin{array}{c}\text { Medios NIES-C } y \\
\text { NIES-N } \\
\text { pH } 7.5 \\
23.4-33.5^{\circ} \mathrm{C}\end{array}$ & $\begin{array}{l}\text { La luz de lámparas } \\
\text { fluorescentes blan- } \\
\text { cas frías a } 35 \mu \mathrm{E} \\
\qquad / \mathrm{m}^{2} / \mathrm{s} \\
\mathrm{CO}_{2}(3-4 \%)\end{array}$ & N. A. & $12: 12 \mathrm{~h}$ & $\begin{array}{c}50 \mu \mathrm{M} \text { de } \\
\text { hierro, } \mathrm{CO}_{2} \\
(3-4 \%) \\
\text { irradiancia } \\
\text { solar } \\
\text { de } 315-380 \mu \mathrm{E} \\
/ \mathrm{m}^{2} / \mathrm{s}\end{array}$ & $\mathrm{N} / \mathrm{A}$ & 5,53. $\mathrm{mg} / \mathrm{L}$ día & $\begin{array}{c}\text { Hong } \\
\text { et al. (2016) }\end{array}$ \\
\hline $\begin{array}{l}\text { BBM } \\
25^{\circ} \mathrm{C}\end{array}$ & $\begin{array}{c}\text { Iluminación } \\
\text { continua } \\
\left(80 \mu \mathrm{mol} \cdot \mathrm{m}^{-2} \cdot \mathrm{s}^{-1}\right)\end{array}$ & $\begin{array}{l}2.23 \times 10^{5} \\
\text { cel./. } \cdot \mathrm{mL}\end{array}$ & $12: 12 \mathrm{~h}$ & $\begin{array}{c}\text { Etanol }(0,0,1, \\
0,2,0,3,0,4 \text { y } \\
0,5 \% v / v)\end{array}$ & 4 días & $4.23 \% \mathrm{DCW}$ & $\begin{array}{l}\text { Liu } \\
\text { et al. (2019) }\end{array}$ \\
\hline $\begin{array}{c}\text { Medio BBM } \\
\text { pH } 7.0 \\
298.15^{\circ} \mathrm{K}\end{array}$ & $\begin{array}{c}\text { Iluminancia de } \\
1.5 \text { klx por } 15 \text { días, } \\
\text { T } 298 \mathrm{~K}\end{array}$ & $\begin{array}{l}1.5 \times 10^{5} \\
\text { cel./. } \mathrm{mL}\end{array}$ & N. A. & $\begin{array}{l}\text { Acetato de } \\
\text { sodio (0.30 } \\
\text { L/min.), pH 7, } \\
\text { T } 298 \mathrm{~K} \\
\text { klx por } 15 \text { días }\end{array}$ & 15 días & $\begin{array}{c}\text { Encapsulación } \\
\text { de astaxantina } \\
\text { eficiencia de } \\
48.25 \%\end{array}$ & $\begin{array}{l}\text { Machado } \\
\text { et al. (2014) }\end{array}$ \\
\hline
\end{tabular}


Torres Ospina, T. y Camacho Kurmen, J. E. (2022). https://doi.org/10.21789/22561498.1743

\begin{tabular}{|c|c|c|c|c|c|c|c|}
\hline $\begin{array}{c}\text { Medio de } \\
\text { cultivo } \\
\text { pH } \\
\text { Temperatura }\end{array}$ & $\begin{array}{l}\text { Luz } \\
\text { Color de luz } \\
\text { Irradiancia }\end{array}$ & $\begin{array}{c}\text { Biomasa } \\
\text { inicial/ } \\
\text { Biomasa } \\
\text { final }\end{array}$ & Fotoperiodo & $\begin{array}{c}\text { Condiciones } \\
\text { de estrés }\end{array}$ & $\begin{array}{c}\text { Tiempo de } \\
\text { estudio }\end{array}$ & $\begin{array}{l}\text { Cantidad de } \\
\text { astaxantina }\end{array}$ & Bibliografía \\
\hline $\begin{array}{c}\text { Medio BBM } \\
\text { modificado } \\
\text { pH } 6.8\end{array}$ & $\begin{array}{l}\text { Luz continua en } \\
\text { lámparas fluores- } \\
\text { centes blancas }\end{array}$ & $\begin{array}{l}6.20 \times 10^{6} \\
\text { cel./. } \mathrm{mL}\end{array}$ & $12: 12 \mathrm{~h}$ & $\begin{array}{l}\mathrm{NaNO}_{3} 0.45, \\
0.60 \text { y } 1.0 \mathrm{~g} / \mathrm{L}\end{array}$ & 4 días & $3,335 \mathrm{mg} / \mathrm{gL}$ & $\begin{array}{c}\text { Montiel } \\
\text { Oviedo (2020) }\end{array}$ \\
\hline $25 \pm 1{ }^{\circ} \mathrm{C}$ & & & & & & & \\
\hline $\begin{array}{l}\text { Medio MES- } \\
\text { Volvox } \\
\text { pH } 6.7\end{array}$ & N. A. & N. A. & $\begin{array}{l}12: 12 \mathrm{~h} \\
120 \mathrm{rpm}\end{array}$ & $\begin{array}{c}\text { Bicarbonato } \\
\text { de sodio } 50 \\
\mathrm{mM}, 2,5 \mathrm{mM} \\
\text { bicarbonato } \\
\text { de sodio }\end{array}$ & 5 días & $\begin{array}{c}11,2 \pm 0,56 \\
\mathrm{mg} / \mathrm{L} .\end{array}$ & $\begin{array}{l}\text { Erturk } \\
\text { (2019) }\end{array}$ \\
\hline $\begin{array}{c}\text { Bold Basal Me- } \\
\text { dium (BBM) }\end{array}$ & $\begin{array}{c}\text { Intensidad baja } 30 \\
\mu \mathrm{mol} \cdot \mathrm{m}^{-2} \cdot \mathrm{s}^{-1} \\
\text { colores: rojo, verde } \\
\text { y azul }\end{array}$ & $\begin{array}{l}5 \times 10^{7} \\
\text { cel. } / \mathrm{mL}\end{array}$ & N. A. & $\begin{array}{c}\text { Nitrato de } \\
\text { sodio } 0.75 \mathrm{~g} / \mathrm{L} \text {, } \\
\mathrm{CO}_{2}(1.5 \%), \mathrm{N} \\
\text { y P } \\
\text { disminuidos, } \\
\text { Luz } 30,80,150 \\
\mu \mathrm{mol} \cdot \mathrm{m}^{-2} \text {. } \\
\mathrm{s}^{-1}\end{array}$ & 8 días & N. A. & $\begin{array}{l}\text { Li et al. } \\
\text { (2019) }\end{array}$ \\
\hline $\begin{array}{c}\text { Medio BG11 } 23 \\
{ }^{\circ} \mathrm{C}\end{array}$ & $\begin{array}{c}400-600 \mu \mathrm{mol} / \mathrm{m}^{2} \\
\mathrm{~s}, \mathrm{pH} 6,5-8,0 \mathrm{~T}: 23 \\
-26^{\circ} \mathrm{C}\end{array}$ & $\begin{array}{l}5-7,5 \\
g / m^{2}\end{array}$ & $14: 10 \mathrm{~h}$ & $\begin{array}{l}\text { Medio sin N y } \\
\text { P, } \mathrm{CO}_{2}(5 \%), \\
700 \mu \mathrm{mol} / \mathrm{m}^{2} \\
\text { s, pH } 6,5-8,0 \\
\mathrm{~T}: 23-26^{\circ} \mathrm{C}\end{array}$ & 10 días & $205 \mathrm{mg} / \mathrm{m}^{2} \mathrm{~d}$ & $\begin{array}{c}\text { Do } \\
\text { et al. (2019) }\end{array}$ \\
\hline $\begin{array}{c}\text { Medio BG-11 } \\
\text { pH } 7 \\
25 \pm 1{ }^{\circ} \mathrm{C}\end{array}$ & $\begin{array}{c}\text { Luz continua, } \\
\text { intensidad de } 30 \\
\mu \mathrm{mol} \mathrm{m}-2 \mathrm{~s}^{-1}\end{array}$ & $0.69 \mathrm{~g} / \mathrm{L}$ & N. A. & $\begin{array}{c}\text { Fitohormonas } \\
\text { (ABA, SA, ETA, } \\
\text { JA) } \\
\text { FA (ácido } \\
\text { fulvico) } 100 \\
\text { mg L }\end{array}$ & $\mathrm{N} / \mathrm{A}$ & & $\begin{array}{c}\text { Zhao } \\
\text { et al. (2019) }\end{array}$ \\
\hline
\end{tabular}


Torres Ospina, T. y Camacho Kurmen, J. E. (2022). https://doi.org/10.21789/22561498.1743

\begin{tabular}{|c|c|c|c|c|c|c|c|}
\hline $\begin{array}{c}\text { Medio de } \\
\text { cultivo } \\
\text { pH } \\
\text { Temperatura }\end{array}$ & $\begin{array}{c}\text { Luz } \\
\text { Color de luz } \\
\text { Irradiancia }\end{array}$ & $\begin{array}{c}\text { Biomasa } \\
\text { inicial/ } \\
\text { Biomasa } \\
\text { final }\end{array}$ & Fotoperiodo & $\begin{array}{c}\text { Condiciones } \\
\text { de estrés }\end{array}$ & $\begin{array}{c}\text { Tiempo de } \\
\text { estudio }\end{array}$ & $\begin{array}{l}\text { Cantidad de } \\
\text { astaxantina }\end{array}$ & Bibliografía \\
\hline $\begin{array}{l}\text { Medio Bristol } \\
\qquad \mathrm{pH}: 6 \\
23^{\circ} \mathrm{C}\end{array}$ & $\begin{array}{l}\text { Luz con lámparas } \\
\text { fluorescentes (PFD) } \\
\text { de } 35 \text { y } 85 \mu \mathrm{mol} \mathrm{m}{ }^{-2} \\
\mathrm{~s}^{-1}, \mathrm{~T} 23^{\circ} \mathrm{C} \text {, fotope- } \\
\text { riodo } 16 \mathrm{~h} \text { luz: } 8 \mathrm{~h} \\
\text { oscuridad, sin } \\
\text { aireación, agitación } \\
2 \text { veces/día, pH } 6.0\end{array}$ & $\begin{array}{l}5 \times 10^{4} \\
\text { cel./ } \mathrm{mL}\end{array}$ & $16: 8 \mathrm{~h}$ & $\begin{array}{l}\text { Acetato de } \\
\text { sodio (4, } 8 \text { y } \\
12 \mathrm{mM} \text { ), Clo- } \\
\text { ruro de sodio } \\
2.0-0.8 \%), \\
\text { deficiencia de } \\
\text { nitrógeno, } 150 \\
\mu \text { mol } \mathrm{m}^{-2} \mathrm{~s}^{-1}\end{array}$ & 31 días & $10.3 \mathrm{mg} \mathrm{g}^{-1}$ & $\begin{array}{l}\text { Cifuentes } \\
\text { et al. (2003) }\end{array}$ \\
\hline $\begin{array}{l}\text { Medio Básico de } \\
\text { Bold (BBM) } \\
25^{\circ} \mathrm{C}\end{array}$ & $\begin{array}{c}\text { Intensidad de luz } \\
\text { de } 40 \mu \mathrm{mol} \mathrm{m}-2 \cdot \mathrm{s} \\
-1\end{array}$ & $\begin{array}{l}1 \times 10^{4} \\
\text { cél./ mL }\end{array}$ & $16: 8 \mathrm{~h}$ & $\begin{array}{c}\text { ácido } \gamma \text {-amino } \\
\text { butírico, GABA } \\
(0,1,5 \text { y } 10 \\
\text { mM) }\end{array}$ & 20 días & & $\begin{array}{c}\text { Li } \\
\text { et al. (2020) }\end{array}$ \\
\hline $\begin{array}{l}\text { Medio basal de } \\
\text { Bold (BBM) } \\
25 \pm 1{ }^{\circ} \mathrm{C}\end{array}$ & $\begin{array}{c}\text { Iluminación } \\
\text { continua a } 30 \mu \mathrm{mol} \\
\mathrm{m}^{-2} \mathrm{~s}^{-1}\end{array}$ & $\begin{array}{c}2 \times 10^{5} \\
\text { cel./ mL / } \\
0,69 \mathrm{~g} / \mathrm{L}\end{array}$ & N. A. & $\begin{array}{l}\text { Melatonina } \\
10 \mu \mathrm{M}\end{array}$ & 15 días & $31.32 \mathrm{mg} / \mathrm{gL}$ & $\begin{array}{c}\text { Ding } \\
\text { et al. (2018) }\end{array}$ \\
\hline $\begin{array}{l}\text { Medio BG-11 } \\
25^{\circ} \mathrm{C}\end{array}$ & $\begin{array}{l}\text { Iluminación me- } \\
\text { diante lámparas led } \\
\text { de color blanco } \\
\text { frío, densidad de } \\
\text { flujo de fotones } \\
\text { (PFD) de } 40 \mu \mathrm{mol} / \\
\mathrm{m}^{2} \mathrm{~s} / 60 \mu \mathrm{mol} / \\
\mathrm{m}^{2} \mathrm{~s} .\end{array}$ & $\begin{array}{c}1.5 \mathrm{mg} / \mathrm{L} / \\
3.4 \pm 0.2 \\
\mathrm{~g} / \mathrm{L}\end{array}$ & N. A. & $\begin{array}{c}\text { Medio sin } \\
\mathrm{KNO}_{3}, \mathrm{CO}_{2} \\
(5-20 \%)\end{array}$ & 6-13 días & & $\begin{array}{l}\text { Chekanovab } \\
\text { et al. (2017) }\end{array}$ \\
\hline $\begin{array}{l}\text { Medio WC } \\
23 \pm 2 \text { oC }\end{array}$ & 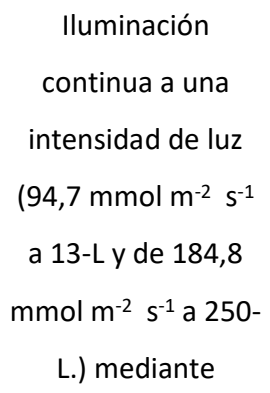 & $\begin{array}{c}0.6 \times 10^{5} \\
\text { cél./mL } \\
1,15 \times 10^{5} \\
\text { cél./.mL }\end{array}$ & N. A. & $\begin{array}{l}\text { Influencia de } \\
\text { volúmenes de } \\
\text { cultivo dife- } \\
\text { rentes (13 L), } \\
\text { baja tasa de } \\
\left(\mathrm{NO}_{3-} \text { ) y P }\right. \\
\text { total }\end{array}$ & 13 días & $\begin{array}{c}\text { Peso seco: } \\
1.82 \%\end{array}$ & $\begin{array}{c}\text { Sipaúba } \\
\text { et al. (2013) }\end{array}$ \\
\hline
\end{tabular}


Torres Ospina, T. y Camacho Kurmen, J. E. (2022). https://doi.org/10.21789/22561498.1743

\begin{tabular}{|c|c|c|c|c|c|c|c|}
\hline $\begin{array}{c}\text { Medio de } \\
\text { cultivo } \\
\text { pH } \\
\text { Temperatura }\end{array}$ & $\begin{array}{c}\text { Luz } \\
\text { Color de luz } \\
\text { Irradiancia }\end{array}$ & $\begin{array}{c}\text { Biomasa } \\
\text { inicial/ } \\
\text { Biomasa } \\
\text { final }\end{array}$ & Fotoperiodo & $\begin{array}{l}\text { Condiciones } \\
\text { de estrés }\end{array}$ & $\begin{array}{c}\text { Tiempo de } \\
\text { estudio }\end{array}$ & $\begin{array}{l}\text { Cantidad de } \\
\text { astaxantina }\end{array}$ & Bibliografía \\
\hline & $\begin{array}{l}\text { lámparas } \\
\text { fluorescentes } \\
\text { blancas frías. }\end{array}$ & & & & & & \\
\hline $\begin{array}{c}\text { Medio BG-11 } \\
\text { pH 7-8 } \\
20-25{ }^{\circ} \mathrm{C}\end{array}$ & $\begin{array}{l}\text { Iluminación } \\
\text { continua de } 30 \\
\mu \mathrm{mol} \mathrm{m}{ }^{-2} \mathrm{~s}^{-1} \text { ) }\end{array}$ & $\begin{array}{l}0.8 \mathrm{~g} / \mathrm{L} / \\
0.30 \mathrm{~g} / \mathrm{L}\end{array}$ & N. A. & $\begin{array}{l}\text { 4,4 } \mathrm{mM} \text { de } \\
\text { nitrógeno }\end{array}$ & $\mathrm{N} / \mathrm{A}$ & $\begin{array}{l}18.71 \pm 2.69 \\
\mathrm{mg} \mathrm{L}^{-1} \mathrm{~d}^{-1}\end{array}$ & $\begin{array}{c}\text { Wang } \\
\text { et al. (2013) }\end{array}$ \\
\hline $\begin{array}{l}\text { BBM-Modificado } \\
\text { pH 6.4-6.6 } \\
25 \pm 5^{\circ} \mathrm{C}\end{array}$ & $\begin{array}{l}\text { Intensidad de luz } \\
52 \mu \mathrm{mol} / \mathrm{m}^{2} \mathrm{~s}\end{array}$ & $\begin{array}{c}0.2 \mathrm{~g} / \mathrm{L} / \\
1.5-1.9 \\
\mathrm{~g} / \mathrm{L}\end{array}$ & $12: 12 \mathrm{~h}$ & $\begin{array}{c}\text { Nitrógeno } \\
\left(\mathrm{NaNO}_{3}\right) \\
\text { y Fósforo } \\
\left(\mathrm{K}_{2} \mathrm{HPO}_{4} \mathrm{y}\right. \\
\left.\mathrm{KH}_{2} \mathrm{PO}_{4}\right) \\
1.0-0.6-0.2 \\
\mathrm{~g} / \mathrm{L}\end{array}$ & 11 días & $168.4 \mathrm{~g} / \mathrm{mL}$ & $\begin{array}{c}\text { Miranda } \\
\text { et al. (2019) }\end{array}$ \\
\hline $\begin{array}{c}\mathrm{OHM} \\
\mathrm{pH} \mathrm{6.5-6.8} \\
25^{\circ} \mathrm{C}\end{array}$ & $\begin{array}{c}\text { Luz led } \\
\text { blancosfríos/ flujo } \\
\text { de fotones fotosin- } \\
\text { téticos de } 20,3 \\
\mathrm{mmol} / \mathrm{m}^{2} / \mathrm{s} \text {. }\end{array}$ & $\begin{array}{c}0,7610^{4} \\
\text { cel. / ml } \\
\text { de culti- } \\
\text { vo/ } \\
3,46710^{2} \\
\text { cél./ } \mathrm{mL} / \\
\text { día }\end{array}$ & $12: 12 \mathrm{~h}$ & $\begin{array}{c}\text { Sonido audible } \\
\text { de } 60 \mathrm{~dB} \text { por } 8 \\
\text { h/ día } \\
\text { Far and Wide y } \\
\text { Blues for Elle } \\
0.24 \text { y } 0.28 \\
\text { kHz }\end{array}$ & 22 días & N. A. & $\begin{array}{c}\text { Christwardana } \\
\text { et al. (2017) }\end{array}$ \\
\hline
\end{tabular}


Torres Ospina, T. y Camacho Kurmen, J. E. (2022). https://doi.org/10.21789/22561498.1743

\begin{tabular}{|c|c|c|c|c|c|c|c|}
\hline $\begin{array}{c}\text { Medio de } \\
\text { cultivo } \\
\text { pH } \\
\text { Temperatura }\end{array}$ & $\begin{array}{c}\text { Luz } \\
\text { Color de luz } \\
\text { Irradiancia }\end{array}$ & $\begin{array}{c}\text { Biomasa } \\
\text { inicial/ } \\
\text { Biomasa } \\
\text { final }\end{array}$ & Fotoperiodo & $\begin{array}{c}\text { Condiciones } \\
\text { de estrés }\end{array}$ & $\begin{array}{c}\text { Tiempo de } \\
\text { estudio }\end{array}$ & $\begin{array}{l}\text { Cantidad de } \\
\text { astaxantina }\end{array}$ & Bibliografía \\
\hline BBM & $\begin{array}{c}\text { Lámparas de luz } \\
\text { blanca, programa- } \\
\text { das para simular un } \\
\text { circuito de cuatro } \\
\text { niveles de ciclo de } \\
\text { circadiano con } \\
\text { diferentes irradian- } \\
\text { cias: } 350,1000 \text {, } \\
\text { 1500, } 2000,2500 \mathrm{E} \\
\mathrm{m}^{-2} \mathrm{~s}^{-1} \text {. }\end{array}$ & $\begin{array}{c}50 \mathrm{mg} / \mathrm{L} \\
\text { /día } \\
0,27 \mathrm{~g} / \mathrm{L} \\
\text { /día }\end{array}$ & N. A. & $\begin{array}{c}\text { Medio basal } \\
\text { nutritivo } \\
\text { concentracio- } \\
\text { nes de } 0,1 \text {, } \\
0,2,0,3,1,0 \text { y } \\
2,0\end{array}$ & 12 días & $\begin{array}{c}1.6 \text { mg L-1 día- } \\
1 .\end{array}$ & García (2005) \\
\hline
\end{tabular}

Fuente: elaboración propia.

Como se pudo observar en las investigaciones relacionadas, el crecimiento de las microalgas se ve afectado por la luz (los cultivos de microalgas están limitados por la luz ya que es fácilmente absorbida y dispersada por las células de microalgas), el oxígeno disuelto, el contenido de dióxido de carbono, el pH, la temperatura, los nutrientes ( $\mathrm{N}$ y $\mathrm{P}$ ), los elementos traza y el carbono. La descripción detallada del comportamiento de la microalga durante el ciclo de vida, utilizando las diferentes condiciones de estrés para la obtención de astaxantina, es importante para establecer las condiciones adecuadas del cultivo y así obtener mayor acumulación de este carotenoide; en consecuencia, es fundamental aplicar la microbiología predictiva, ya que describe, por medio de modelos matemáticos, la evolución de la población microbiana bajo diferentes condiciones ambientales, como las de estrés.

Con las condiciones estándar y bajo condiciones de estrés, se pueden estimar las diferentes fases de crecimiento, la duración, la máxima velocidad específica de crecimiento ( $\mu$ máx), la máxima biomasa de microalga (células $/ \mathrm{mL}$ ), el tiempo de duplicación ( $\mathrm{Td}$ ), la fijación de $\mathrm{CO}_{2}$, la productividad de biomasa (células $/ \mathrm{mL}$ día) y del pigmento de interés ( $\mu \mathrm{g} / \mathrm{mL}$ día de astaxantina); así como los parámetros cinéticos que se pueden obtener a través de la aplicación de modelos matemáticos como el logístico, el de Baranyi y Roberts y el Gompertz, cuya aplicación describe la forma adecuada del crecimiento, los parámetros que lo afectan y lo caracterizan; por ello, se define el modelo que más se ajuste al comportamiento de la microalga, para establecer las condiciones adecuadas de crecimiento y de obtención del pigmento en mayor cantidad, y poder proyectarlo hacia condiciones de escalamiento y producción a nivel industrial.

La microbiología predictiva es una rama de la microbiología que intenta describir el comportamiento de un microorganismo bajo unas condiciones ambientales dadas a través de modelos matemáticos. En este campo, 
Garre Pérez et al. (2016) publican el artículo "Modelos matemáticos para la descripción del crecimiento de microorganismos patógenos en alimentos", en el que presentan los modelos matemáticos más utilizados actualmente para la descripción de crecimiento microbiano. Niño et al. (2017), en su artículo "Evaluación de las condiciones de crecimiento celular para la producción de astaxantina a partir de la microalga $H$. pluvialis", encuentran el mayor crecimiento celular en el medio RM con $7,5 \times 10^{5} \mathrm{cel}$. $/ \mathrm{ml}$ en el día 36; utilizando el modelo logístico, establecieron una velocidad de crecimiento de 0.092 cél./día, con un ajuste del modelo en un 0.97 y una mayor producción de astaxantina con una concentración de $8.3 \mu \mathrm{g} / \mathrm{ml}$.

A pesar del avance que se ha tenido en el estudio de esta microalga, el reto es obtener mayor productividad de biomasa, ya que esto repercutirá en la cantidad de astaxantina que se produce durante el proceso de síntesis para su uso comercial, lo cual es ciertamente importante en términos económicos. Cruz Jiménez et al. (2017) realizaron una investigación titulada Cultivo masivo de la microalga Haematococcus sp. en fotobiorreactores planos para la producción de astaxantina bajo diferentes condiciones de estrés, que tuvo como objetivo cultivar la microalga en fotobiorreactores planos para producir la mayor cantidad de biomasa con la máxima densidad celular posible, y posteriormente inducir la producción de carotenoides, principalmente astaxantina, al someterlas a condiciones de estrés, como altas intensidades de luz y salinidad. Los resultados indicaron que la intensidad de luz de $282 \mu \mathrm{mol} \cdot \mathrm{m}^{-2} \mathrm{~s}^{-1}$, junto con el incremento de la temperatura de $39^{\circ} \mathrm{C}$, produjeron la mayor cantidad de carotenoides.

A través del tiempo, se ha buscado poder representar la relación existente entre la célula y su medio ambiente en los modelos de bioprocesos. En este sentido, Ortega et al. (2017) publican el artículo "Enfrentando el modelado de bioprocesos: una revisión de las metodologías de modelado", donde exponen una revisión detallada de las diferentes metodologías para el modelado de procesos, señalando sus deficiencias y limitaciones al ser aplicadas y su función en industrias de alimentos, químicas y farmacéuticas. El uso de los modelos cinéticos de crecimiento de microalgas como el logístico, Baranyi-Roberts, Monod y Gompertz reportan parámetros cinéticos útiles relacionados con la producción de biomasa, el tiempo de duplicación, el consumo de nutrientes y la productividad, proporcionando datos esenciales para seleccionar las condiciones adecuadas para el cultivo de la microalga $H$. pluvialis y la producción de astaxantina de alta eficiencia.

El modelo propuesto por Monod crea una relación hiperbólica entre el crecimiento y un factor externo (carbono orgánico, nutrientes, oxígeno, irradiancia), definida por el máximo específico de tasa de crecimiento y constante de semisaturación (mitad de la tasa máxima), el cual es revisado por Shoener et al. (2018) en su publicación "Microalgae and cyanobacteria modeling in water resource recovery facilities: A critical review".

Al momento de cultivar $H$. pluvialis a gran escala, además de sus específicas condiciones para la producción de astaxantina, deben tenerse en cuenta sus altos costos. En el artículo "Media effects on laboratory scale production costs of Haematococcus pluvialis biomass", Colusse et al. (2019) tuvieron como objetivo realizar un análisis económico y evaluar las características fisiológicas y el rendimiento del crecimiento de la biomasa producida a partir de $H$. pluvialis en etapa vegetativa, utilizando medios CHU, BG-11 y WC en cultivo discontinuo. Los resultados arrojaron una mayor densidad celular mediante el uso de medios CHU y BG-11 para el día 16 de cultivo, mientras que el medio $\mathrm{CHU}$ promovió el mayor contenido 
de pigmento durante el periodo de cultivo de microalgas. El análisis económico mostró que los componentes de NPK contribuyeron al mayor costo de participación en la composición de los medios.

El uso de sales de bicarbonato como un medio para entregar eficientemente carbono inorgánico en microalgas es un concepto relativamente nuevo y su aplicación está en continuo crecimiento. Algunos estudios se han centrado principalmente en aumentar el contenido de lípidos en las microalgas mediante el uso de altas concentraciones de bicarbonato de sodio en condiciones de cultivo con deficiencia de nitrógeno, por lo que su acumulación está directamente relacionada con la producción de astaxantina, ya que se disuelve y se almacena en cuerpos lipídicos en $H$. pluvialis. Por este motivo, Erturk (2019) realiza su investigación titulada Sodium bicarbonate amendment for enhanced astaxanthin production from Haematococcus pluvialis, cuyo objetivo es el estudio de la adición de bicarbonato de sodio sobre la producción de astaxantina.

En esta contribución se presentan los modelos matemáticos más utilizados para la descripción de crecimiento microbiano, como el publicado por Nilanjana et al. (2019): "Effect of culturing parameters on the vegetative growth of Haematococcus alpinus (Strain Lcr-Cc-261f) and modeling of its growth kinetics", en el que ajustaron los parámetros a una forma de la ecuación logística sobre el crecimiento vegetativo de una nueva especie de Haematococcus (H. alpinus). La ecuación logística definida por Verhulst se usa comúnmente para modelar microalgas cinéticas de crecimiento. Este modelo emplea tres parámetros clave: densidad celular inicial en el tiempo cero (NO, células $\mathrm{mL1}$ ), celda de máxima densidad que se puede alcanzar teóricamente ( $\mathrm{Nt}$, células $\mathrm{mL1}$ ) y tasa máxima de crecimiento específico (Imax, d1).

Los modelos matemáticos son una herramienta esencial y poderosa para estudiar y analizar el crecimiento de microalgas en diferentes condiciones fisiológicas. Por esto, Ortiz-Moreno et al. (2020), en su artículo "Modeling the effects of light wavelength on the growth of Nostoc ellipsosporum", analizaron otros modelos matemáticos aplicados, como el propuesto por Gompertz, el cual combinaría los modelos cinéticos de crecimiento con los modelos primarios deterministas (dependiendo del tipo de parámetros y variables con respecto al tiempo) y, a su vez, el modelo modificado propuesto por Baranyi-Roberts, los cuales abarcan una concepción mecanicista e incluyen parámetros y funciones con significado biológico.

\section{Modelos de crecimiento}

El modelado matemático es una herramienta empleada para describir la respuesta celular de las microalgas a los cambios en los insumos de nutrientes y otros factores ambientales, como el uso de condiciones de estrés. Actualmente, no existe un modelo preciso que incorpore simultáneamente entradas multiparamétricas como carbono, nitrógeno, fósforo e intensidad lumínica como parámetros definitorios para la vida útil de las microalgas (Tijani et al., 2018).

El modelado del crecimiento microbiano se realiza usualmente en dos pasos. En primer lugar, se puede usar cualquier parámetro cinético como la relación entre el tamaño de la población microbiana $(\mathrm{N})$ y el tiempo $(\mathrm{t})$, que se describe a través de un modelo matemático, bajo un solo conjunto de condiciones ambientales (Garre Pérez et al., 2016; Longhi et al., 2017), conocido como el modelo primario. En un segundo paso, la relación entre los parámetros del modelo primario bajo la influencia de la temperatura, el pH, la actividad de agua, la concentración de 
sales, etc., sobre los parámetros del modelo primario, que se describe a través de un segundo modelo matemático (modelo secundario) (Garre Pérez et al., 2016).

\section{Curva de crecimiento y fases}

El crecimiento de un microorganismo suele ilustrarse a través de la curva de crecimiento sigmoidea, que es la representación del logaritmo del número de microorganismos con respecto al tiempo, usualmente en condiciones favorables para el crecimiento. Sin embargo, el microorganismo necesita un tiempo para adaptarse a ese nuevo ambiente (Garre Pérez et al., 2016). La curva de crecimiento de un cultivo microbiano puede ser subdividida en cuatro partes distintas: fase de latencia, fase exponencial, fase estacionaria y fase de muerte (Shuler y Kargi, 2002; Sancho, 2015), como se describe a continuación (figura 4, tabla 2):

Fase de latencia o fase lag: Es el periodo de ajuste que las células experimentan al ser transferidas de un medio al otro antes de iniciar su crecimiento.

Fase exponencial o logarítmica: Es aquella durante la cual los microorganismos crecen y se dividen hasta el nivel máximo posible, en función de su potencial genético, tipo de medio y las condiciones en que crece y el tiempo.

Fase estacionaria: Es resultado del agotamiento de los nutrientes disponibles o del efecto de acumulación de productos tóxicos de metabolismo que tienen como consecuencia la disminución de la velocidad del crecimiento. La transición entre estas dos fases se caracteriza por un crecimiento desequilibrado, durante el cual los diversos componentes celulares son sintetizados a diferentes velocidades.

Fase de muerte: Es consecuencia de diversos factores, como el agotamiento de las reservas celulares de energía. Al igual que el crecimiento, la muerte también asume una función exponencial que puede ser representada por una disminución lineal del número de células viables a lo largo del tiempo.

Figura 2. Fases de crecimiento de microalga: 1. Adaptación (fase lag). 2. Fase de aceleración de la fase de crecimiento. 3. Crecimiento exponencial (fase log). 4. Fase de desaceleración indicando la disminución del crecimiento log (crecimiento lineal). 5. Fase estacionaria. 6. Muerte acelerada. 7. Muerte.

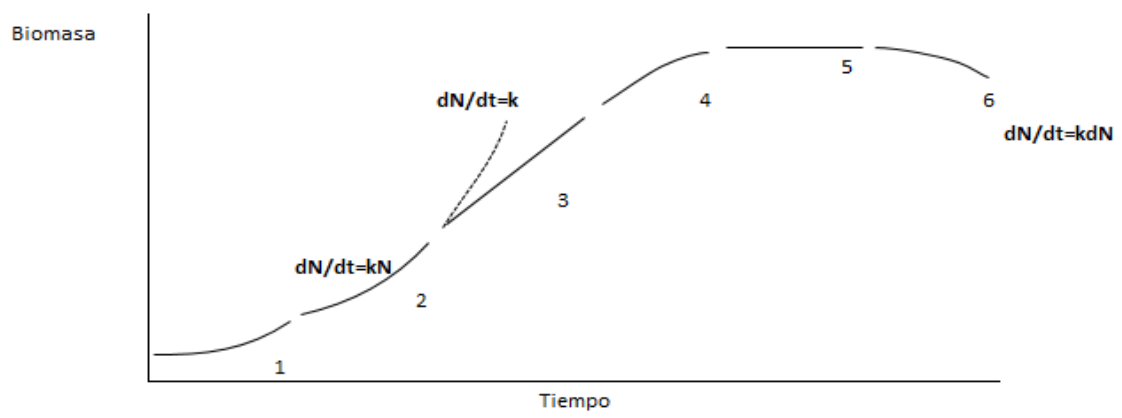

Fuente: Shuler y Kargi (2002). 
Tabla 2. Modelos matemáticos y parámetros cinéticos de crecimiento

\begin{tabular}{|c|c|c|c|}
\hline Modelo & Ecuación & Parámetros & Citación \\
\hline Logístico & $\mu=\mu \max \left(1-\frac{x}{X \max }\right)[1]$ & $\begin{array}{l}\mu=\text { Tasa de crecimiento específico [d-1] } \\
\begin{array}{l}\mu \mathrm{max}=\text { Tasa máxima de crecimiento } \\
\text { específico }\end{array} \\
\text { X= concentración de biomasa [g.m-3] } \\
\text { Xmax = concentración máxima de bioma- } \\
\text { sa [g.m-3] }\end{array}$ & $\begin{array}{c}\text { Shoener } \\
\text { et al. (2019) }\end{array}$ \\
\hline Monod & $\mu=\mu \max \left(\frac{s}{\mathbb{N} s+s}\right)[2]$ & $\begin{array}{l}\text { Ks = Constante de media saturación } \\
\qquad\left[\mathrm{g} \cdot \mathrm{m}-{ }^{3}\right] \\
\mathrm{S}=\text { Concentración de sustrato }\end{array}$ & $\begin{array}{c}\text { Shoener } \\
\text { et al. (2019) }\end{array}$ \\
\hline Baranyi-Roberts & $\begin{array}{c}\frac{d N}{d t}=\alpha(t) \cdot \mu \max \cdot \gamma(t) \cdot N(t) \\
{[3]}\end{array}$ & $\begin{array}{c}\mathrm{N}=\text { Número de microorganismos } \\
\mathrm{T}=\text { Tiempo } \\
\mu \mathrm{max}=\text { Ratio de crecimiento específico } \\
\text { (fase exponencial) } \\
\mu(\mathrm{t})=\text { Ratio cinético de crecimiento } \\
a(t)=\text { Fase de adeptación } \\
\gamma(t)=\text { Fase estacionaria }\end{array}$ & $\begin{array}{l}\text { Garre Pérez } \\
\text { et al. (2016) }\end{array}$ \\
\hline Gompertz & $N(t)=C \exp \left(-n c \cdot e^{-k t}\right)[4]$ & $\begin{array}{c}\text { N = Población } \\
\mathrm{C}=\text { Capacidad de carga del medio } \\
\mathrm{K}=\text { es el máximo crecimiento fraccional }\end{array}$ & $\begin{array}{l}\text { Orlandoni y Ramoni } \\
\qquad(2017)\end{array}$ \\
\hline
\end{tabular}

Fuente: elaborado por los autores, 2021. 


\section{Parámetros cinéticos de crecimiento}

Los modelos cinéticos estiman la respuesta de crecimiento específica con respecto a diferentes variables, como la concentración gaseosa, el potencial de óxido-reducción, la humedad relativa, el contenido de nutrientes y propiedades antimicrobianas, o variables ambientales como la temperatura, el pH o la aw. (Garre Pérez et al., 2016). El crecimiento celular y la evaluación de parámetros cinéticos para monitorear el crecimiento celular se puede realizar diariamente mediante la medición de la concentración celular por triplicado, determinada por la densidad óptica del cultivo, utilizando una longitud de onda de $670 \mathrm{~nm}$ en un espectrofotómetro, por conteo celular (células/ml) o por peso seco de biomasa (gr) (De Mendonça et al., 2018).

La concentración celular se obtiene a través de una curva estándar sobre peso seco y densidad óptica (X máxima). Con estos datos, la productividad máxima ( $P$ máxima) se calcula con la tasa de crecimiento específica máxima ( $\mu_{\text {máx }}$ y el tiempo de generación (tg). La productividad $\left(P, g \cdot \frac{L}{d}\right)$ se calcula según la ecuación, donde $X\left(\frac{g}{L}\right)$ representa la concentración celular final, $\left.X O\left(\frac{g}{L}\right)\right)$ representa la concentración de cultivo inicial de biomasa, $t(d)$ representa el tiempo final y to representa el tiempo inicial de cultivo:

$$
P=\frac{(X-X o)}{(t-t o)}
$$

La máxima velocidad de crecimiento (tasa de crecimiento) ( $\mu_{\text {máx.) }}$ se obtiene por regresión exponencial en la fase exponencial (fase log), donde se multiplican las células, y el tiempo de generación se obtiene de la siguiente ecuación:

$$
\operatorname{tg}=\frac{\operatorname{Ln} 2}{\mu m a ́ x .}
$$

Como complemento al monitoreo, se mide cada 24 horas el $\mathrm{pH}$ del cultivo (69), el oxígeno disuelto ( $\mathrm{mg} / \mathrm{L}$ ), la conductividad, la productividad del colorante de interés $(\mu \mathrm{g} / \mathrm{L} \mathrm{d})$, el contenido de nitrógeno $(\mu \mathrm{g} / \mathrm{L})$ y de fósforo $(\mu \mathrm{g} / \mathrm{L})$ para cada uno de los ensayos realizados (De Mendonça et al., 2018).

\section{Fijación de $\mathrm{CO}_{2}$}

La acumulación de $\mathrm{CO}_{2}$ se determina según la ecuación:

$\mathrm{FA}=(\mathrm{Xt}-\mathrm{Xo})$ mcbm Vbiorreactor $(\mathrm{MCO} 2 / \mathrm{Mc})$

Donde:

$$
\text { Xt }\left(\frac{g}{L}\right) \text { es la concentración celular en el tiempo } t(d) \text {. }
$$


Xo $\left(\frac{g}{L}\right)$ es la concentración a tiempo to.

mcbm $\left(\frac{g e}{\text { gamostra }}\right)$ es el peso de la fracción de carbono determinada en la biomasa microalgal.

$\checkmark$ biorreactor es el volumen de medio del biorreactor.

$\mathrm{MCO}_{2}(\mathrm{~g} / \mathrm{mol})$ y $\mathrm{Mc}$ son la masa molecular de $\mathrm{CO}_{2}$ y de carbono (De Mendonça et al., 2018).

Con las curvas de crecimiento generadas en el cultivo de la microalga a condiciones estándar y bajo condiciones de estrés, se pueden estimar las diferentes fases de crecimiento, la máxima velocidad específica de crecimiento ( $\mu$ máx), la máxima biomasa de microalga (células $/ \mathrm{mL}$ ), el tiempo de duplicación (Td), la fijación de $\mathrm{CO}_{2}$, la productividad de biomasa (células $/ \mathrm{mL}$ día) y del pigmento de interés $(\mu \mathrm{g} / \mathrm{mL}$ día de astaxantina). Los parámetros cinéticos se pueden obtener a través de la aplicación de modelos matemáticos como el logístico, el de Baranyi y Roberts y el Gompertz, cuya aplicación describe la forma adecuada del crecimiento, los parámetros que lo afectan y lo caracterizan, definiendo el modelo que más se ajuste al comportamiento de la microalga, para establecer las condiciones óptimas de crecimiento y de obtención del pigmento en mayor cantidad, y poder proyectarlo hacia condiciones de producción a nivel industrial.

En la tabla 3 se presentan los modelos de crecimiento y los parámetros cinéticos estimados para el seguimiento del cultivo de $H$. pluvialis, en los cuales se aplican diferentes condiciones de crecimiento. Conocer los modelos y los parámetros cinéticos determinados ayudará a optimizar el rendimiento del proceso, las condiciones de cultivo y los sistemas de escalado para la tecnología comercial basada en microalgas, como se muestra en el estudio de Lobaton et al. (2017), donde el propósito de la aplicación del modelo era predecir los tiempos adecuados para la adición de nitrato para el cultivo de la microalga.

Tabla 3. Modelos matemáticos y parámetros cinéticos de crecimiento del cultivo de $H$. pluvialis

\begin{tabular}{|c|c|c|c|c|c|c|c|}
\hline Modelo & $\begin{array}{l}\text { Medio de } \\
\text { cultivo }\end{array}$ & $\begin{array}{c}\text { Biomasa } \\
\text { inicial (Xo) }\end{array}$ & $\begin{array}{c}\text { Biomasa final } \\
\text { xf) }\end{array}$ & $\begin{array}{l}\text { Velocidad de } \\
\text { crecimiento } \\
(\mu)\left(d^{-1}\right)\end{array}$ & Td (días) & $\begin{array}{c}\text { Coeficiente de } \\
\text { determina- } \\
\text { ción }\left(\mathbf{R}^{2}\right)\end{array}$ & Bibliografía \\
\hline \multirow{3}{*}{ Logístico } & RM & 4 & 5.878 & 0.092 & 7.534 & 0.97 & \multirow{3}{*}{$\begin{array}{c}\text { Niño } \\
\text { et al. (2017) }\end{array}$} \\
\hline & онм & 4 & 5.535 & 0.062 & 11.179 & 0.99 & \\
\hline & BBM & 4 & 5.588 & 0.056 & 12.377 & 0.97 & \\
\hline Hiperbólico & $\begin{array}{c}\text { Medio de } \\
\text { cultivo están- } \\
\text { dar }\end{array}$ & $50 \mathrm{mg} / \mathrm{L}-1 /$ & $\begin{array}{c}0.3 \text { g } L-1 \text { día } \\
-1\end{array}$ & $0.11 / \mathrm{h}$ & 6.301 & 0.9778 & $\begin{array}{l}\text { García-Malea } \\
\text { et al. (2005) }\end{array}$ \\
\hline
\end{tabular}


Torres Ospina, T. y Camacho Kurmen, J. E. (2022). https://doi.org/10.21789/22561498.1743

\begin{tabular}{|c|c|c|c|c|c|c|c|}
\hline Modelo & $\begin{array}{l}\text { Medio de } \\
\text { cultivo }\end{array}$ & $\begin{array}{c}\text { Biomasa } \\
\text { inicial (Xo) }\end{array}$ & $\begin{array}{c}\text { Biomasa final } \\
\text { Xf) }\end{array}$ & $\begin{array}{l}\text { Velocidad de } \\
\text { crecimiento } \\
(\mu)\left(d^{-1}\right)\end{array}$ & Td (días) & $\begin{array}{c}\text { Coeficiente de } \\
\text { determina- } \\
\text { ción }\left(\mathbf{R}^{2}\right)\end{array}$ & Bibliografía \\
\hline $\begin{array}{l}\text { Baranyi y } \\
\text { Roberts }\end{array}$ & RM & 4 & 6,683 & 0.030 cel./día & 23.105 & 0,87 & \multirow{3}{*}{$\begin{array}{c}\text { Gómez } \\
\text { et al. (2019) }\end{array}$} \\
\hline $\begin{array}{l}\text { Baranyi y } \\
\text { Roberts }\end{array}$ & $\begin{array}{c}\text { RM con } \\
\text { Nitrógeno } 4 \%\end{array}$ & 4 & 6,571 & 0.029 cel./día & 23.901 & 0,92 & \\
\hline $\begin{array}{l}\text { Baranyi y } \\
\text { Roberts }\end{array}$ & $\begin{array}{c}\text { RM con } \\
\text { Nitrógeno 5\% }\end{array}$ & 4 & 6,559 & 0.028 cel./día & 24.755 & 0,90 & \\
\hline Exponencial & $\begin{array}{c}\mathrm{N}_{1} \mathrm{P}_{1} \\
\text { 1.0:1.0 }\end{array}$ & $\begin{array}{c}0.226( \pm) \\
0.028\end{array}$ & & $\begin{array}{c}0.196( \pm) \\
0.021\end{array}$ & $\begin{array}{c}3.525( \pm) \\
0.357\end{array}$ & $\begin{array}{c}0.979( \pm) \\
0.075\end{array}$ & \multirow{2}{*}{$\begin{array}{c}\text { Miranda } \\
\text { et al. (2019) }\end{array}$} \\
\hline Exponencial & $\begin{array}{c}\mathrm{N}_{1} \mathrm{P}_{\mathrm{O}} \\
\text { 1.0:1.0 }\end{array}$ & $\begin{array}{c}0.062( \pm) \\
0.013\end{array}$ & & $\begin{array}{c}0.179( \pm) \\
0.031\end{array}$ & $\begin{array}{c}3.855( \pm) \\
0.053\end{array}$ & $\begin{array}{c}0.974( \pm) \\
0.095\end{array}$ & \\
\hline Logístico & F1 & $1 \times 10^{5} \mathrm{Cel} / \mathrm{mL}$ & $\begin{array}{c}3.87 \times 10^{6} \\
\text { Cel. } / \mathrm{mL}\end{array}$ & 0.63 & 1.100 & & $\begin{array}{l}\text { Issarapayup } \\
\text { et al. (2011) }\end{array}$ \\
\hline Logístico & BG-11 & $\begin{array}{l}2.0 \times 10^{4} \\
\text { Cel. } / \mathrm{mL}\end{array}$ & $\begin{array}{c}10.5 \times 10^{4} \\
\text { Cel. } / \mathrm{mL}\end{array}$ & 0.17/día & 4.1 & & $\begin{array}{c}\text { Nilanjana } \\
\text { et al. (2019) }\end{array}$ \\
\hline Logístico & $\begin{array}{l}\text { MLA con nitra- } \\
\text { to de sodio } \\
\text { (40 mM) }\end{array}$ & $\begin{array}{l}2.0 \times 10^{4} \\
\text { Cel. } / \mathrm{mL}\end{array}$ & $\begin{array}{c}63.5 \times 10^{4} \\
\text { Cel. } / \mathrm{mL}\end{array}$ & 0.44/día & 1.6 & & $\begin{array}{c}\text { Nilanjana } \\
\text { et al. (2019) }\end{array}$ \\
\hline Monod & BG-11 & $\begin{array}{c}0.1,0.5,0.8 \\
1.5,2.7,3.5, y \\
5.0 \mathrm{~g} / \mathrm{L}-\end{array}$ & $7 \mathrm{~g} / \mathrm{L}$ & $0.6 \mathrm{~g} / \mathrm{d}$ & 1.155 & & $\begin{array}{c}\text { Wang } \\
\text { et al. (2013) }\end{array}$ \\
\hline Monod & $\begin{array}{l}\text { Agua residual } \\
\text { con antibióti- }\end{array}$ & $2.79 \mu \mathrm{g} / \mathrm{L}$ & $103.7 \mu \mathrm{g} / \mathrm{L}$ & 0.24/día & 2.888 & $0.67-0.98$ & $\begin{array}{c}\text { Kiki } \\
\text { et al. (2020) }\end{array}$ \\
\hline
\end{tabular}


Torres Ospina, T. y Camacho Kurmen, J. E. (2022). https://doi.org/10.21789/22561498.1743

\begin{tabular}{|c|c|c|c|c|c|c|c|}
\hline Modelo & $\begin{array}{l}\text { Medio de } \\
\text { cultivo }\end{array}$ & $\begin{array}{c}\text { Biomasa } \\
\text { inicial (Xo) }\end{array}$ & $\begin{array}{c}\text { Biomasa final } \\
\text { Xf) }\end{array}$ & $\begin{array}{l}\text { Velocidad de } \\
\text { crecimiento } \\
(\mu)\left(d^{-1}\right)\end{array}$ & Td (días) & $\begin{array}{c}\text { Coeficiente de } \\
\text { determina- } \\
\text { ción }\left(\mathbf{R}^{2}\right)\end{array}$ & Bibliografía \\
\hline & $\cos$ & & & & & & \\
\hline $\begin{array}{l}\text { Modelo ciné- } \\
\text { tico diseñado }\end{array}$ & $\begin{array}{c}\text { Medio con } \\
\text { acetato de } \\
\text { sodio cultivo } \\
\text { por lote }\end{array}$ & $\begin{array}{l}2.2 \times 10^{4} \\
\text { Cel. } / \mathrm{mL}\end{array}$ & $2.92 \mathrm{~g} \mathrm{~L}-1$ & 0.5258/día & 1.318 & & $\begin{array}{c}\text { Zhang } \\
\text { et al. (1999) }\end{array}$ \\
\hline $\begin{array}{l}\text { Modelo ciné- } \\
\text { tico diseñado }\end{array}$ & $\begin{array}{c}\text { Medio con } \\
\text { acetato de } \\
\text { sodio cultivo } \\
\text { semicontinuo }\end{array}$ & $\begin{array}{l}2.2 \times 10^{4} \\
\text { Cel. } / \mathrm{mL}\end{array}$ & $3.31 \mathrm{~g} \mathrm{~L}-1$ & 0.6727/día & 1.030 & & $\begin{array}{c}\text { Zhang } \\
\text { et al. (1999) }\end{array}$ \\
\hline
\end{tabular}

Fuente: elaboración propia.

La correlación entre los valores calculados de los parámetros cinéticos del modelo y los valores referenciados de los parámetros fisiológicos de la microalga, como las condiciones de estrés utilizadas, deficiencia de nutrientes como nitrógeno y/fosfato, estrés con cloruro de sodio y/o acetato de sodio combinados con alta irradiancia (tabla 2), demuestran la importancia de los modelos para explicar cómo influyen las condiciones empleadas para el cultivo y cuáles son las óptimas de acuerdo con cómo se ajuste el modelo, para establecer las adecuadas para el crecimiento y la obtención del pigmento en mayor cantidad, y poder proyectarlo hacia condiciones de escalamiento a nivel industrial.

Los modelos de crecimiento utilizados, como el logístico, exponencial, Baranyi y Roberts, y Monod, se ajustan al crecimiento de la microalga bajo las condiciones trabajadas en los cultivos realizados, lo cual se expresa en los coeficientes de correlación con valores cercanos a 1 . Esto garantiza el cultivo bajo estas condiciones y valida los datos encontrados; así, son los modelos logístico y Monod los que más se ajustan al cultivo de la microalga bajo las condiciones reportadas para cada estudio $\left(R^{2}=1\right)$.

En algunos estudios se determinó la productividad de la biomasa (g L-1 d1), calculándose como: productividad de biomasa $=(\mathrm{DWt}-\mathrm{DW} 0) / \mathrm{t}$, donde DWt y DW0 representan biomasa en el día $t$ y día 0 y ( $\mathrm{t}$ ) representa el tiempo de cultivo. Lo cual se puede expresar por etapa roja o verde, obteniéndose una productividad media de biomasa del cultivo de etapa verde de $H$. pluvialis de $0.1 \mathrm{~g} \mathrm{L-1} \mathrm{d-1.} \mathrm{Tam-}$ bién se reporta la máxima productividad de astaxantina de $18.71 \pm 2.69 \mathrm{mg} \mathrm{L}-1 \mathrm{~d}$ 1 (Wang et al., 2013).

\section{Conclusiones}

La optimización y control de los bioprocesos requieren el establecimiento de modelos matemáticos que describen la cinética de variables del proceso, como crecimiento microbiano ( $\mu \mathrm{max})$, tiempo de duplicación (td), biomasa inicial 
$(\mathrm{Xo})$, biomasa final $(\mathrm{Xf})$, consumo de sustrato y formación de producto, productividad de biomasa $(\mathrm{Yx} / \mathrm{Ys})$ y productividad de carotenoide $(\mathrm{Yp} / \mathrm{Ys})$, los cuales son validados por el coeficiente de correlación $\left(\mathrm{R}^{2}\right)$ por su cercanía a 1 . Se ha progresado en el desarrollo de modelos cinéticos utilizando la irradiancia como parámetro por tener en cuenta y se aplican en la práctica al cultivo de $H$. pluvialis los modelos estructurados como el de Monod, Barany-Roberts y logístico.

La aplicación y entendimiento de los modelos matemáticos y el efecto y establecimiento de los parámetros cinéticos más relevante optimizarán el cultivo de esta microalga y la obtención de la astaxantina usada como colorante y compuesto bioactivo. Los parámetros cinéticos utilizados para el monitoreo del cultivo de la microalga $H$. pluvialis que llevan a una buena producción de astaxantina son: usar medios de cultivo como RM, BBM, OHM y BG11 bajo condiciones de $\mathrm{pH} 7$, fotoperiodo 20/4, temperatura de $25 \stackrel{\circ}{\circ} \mathrm{C}$, agitación continua, $\mathrm{CO}_{2} 5 \%$ e iluminación con lámparas fluorescentes blancas $40 \mathrm{umol} / \mathrm{m} 2 \mathrm{~s}$. La concentración de astaxantina se encontró con valores entre 2.5 hasta $354 \mathrm{mg} / \mathrm{L}$. Usando biomasas iniciales de la microalga entre $1 \times 10^{4}$ cél. $/ \mathrm{mL}$ hasta valores de $10^{6}$ cél. $/ \mathrm{mL}$, con velocidad de crecimiento entre 0.029 cél./día hasta 0.6727 cél./día y tiempo de duplicación entre 0.67 hasta 0.99 .

\section{Referencias}

Allewaert, C. C., Vanormelingen, P., Pröschold, T., Gómez, P. I., González, M. A., Bilcke, G., y Vyverman, W. (2015). Species diversity in European Haematococcus pluvialis (Chlorophyceae, Volvocales). Phycologia, 54(6), 583-598. https://doi.org/10.2216/15-55.1

Barbosa, C., Beltrán-Rocha, J., Mora-Zúñiga, A., Gallegos-López, J. A., López, U., Galán-Wong, L. J., Quintero-Zapata, I., y Elías-Santos, M. (2018). Evaluación de la actividad antioxidante de los carotenoides totales producidos por la microalga Haematococcus Pluvialis bajo distintos periodos de estrés. Revista de Ciencias Farmacéuticas y Biomedicina, 1.

Camacho, J. E., González, G., y Klotz, B. (2013). Producción de astaxantina en Haematococcus pluvialis bajo diferentes condiciones de estrés. NOVA, 11(19). https://doi.org/10.22490/24629448.1022

Çelekli, A., Balcı, M., y Bozkurt, H. (2008). Modelling of Scenedesmus obliquus; function of nutrients with modified Gompertz model. Bioresource Technology, 99(18), 8742-8747. https://doi.org/10.1016/j.biortech.2008.04.028

Chekanovab, K., Schastnayaa, E., Solovchenkoa, A., y Lobakovaa, E. (2017). Effects of $\mathrm{CO} 2$ enrichment on primary photochemistry, growth and astaxanthin accumulation in the chlorophyte Haematococcus pluvialis. Journal of Photochemistry and Photobiology B: Biology, 171, 58-66. https://doi.org/10.1016/j.jphotobiol.2017.04.028

Christwardana, M., y Hadiyanto, H. (2017). The effects of audible sound for enhancing the growth rate of microalgae Haematococcus pluvialis in vegetative stage. HAYATI Journal of Biosciences, 24(2017), 149-155. https://doi.org/10.1016/j.hjb.2017.08.009 
Cifuentes, A. S., González, M. A., Vargas, S., Hoeneisen, M., y González, N. (2003). Optimization of biomass, total carotenoids and astaxanthin production in Haematococcus pluvialis Flotow strain Steptoe (Nevada, USA) under laboratory conditions. Biological Research, 36(3-4). http://dx.doi.org/10.4067/S071697602003000300006

Colusseab, G. A, Rabello, M. E, Duartea, J. C, Carvalho, M., y Nosedaa, D. (2019). Media effects on laboratory scale production costs of Haematococcus pluvialis biomass. Bioresource Technology Reports, 7, 100236. https://doi.org/10.1016/j.biteb.2019.100236

Córdoba-Castro, N. M., Acero-Reyes, N. L., Duque-Buitrago, L. F., JiménezAguilar, L. J., y Serna-Jiménez, J. A. (2015). Obtención y caracterización de astaxantina de la microalga Haematococcus Pluvialis. UG Ciencia, 21, 73-82. https://doi.org/10.18634/ugcj.21v.1i.426

Cruz Jiménez, M. A. (2017). Cultivo masivo de la microalga Haematococcus $s p$. en fotobiorreactores planos para la producción de astaxantina bajo diferentes condiciones de estrés [tesis de maestría]. Ensenada: Centro de Investigación Científica y de Educación Superior de Ensenada, Baja California.

De Mendonça, H. V., Ometto, J. P. H. B., Otenio, M. H., Marques, I. P. R. y Dos Reis, A. J. D. (2018). Microalgae-mediated bioremediation and valorization of cattle wastewater previously digested in a hybrid anaerobic reactor using a photobioreactor: comparison between batch and continuous operation. Science of the Total Environment, 633, 1-11.https://doi.org/10.1016/j.scitotenv.2018.03.157

Ding, W., Zhao, P., Peng, J., Zhao, Y., Xu, J.-W., Li, T., y Yu, X. (2018). Melatonin enhances astaxanthin accumulation in the green microalga Haematococcus pluvialis by mechanisms possibly related to abiotic stress tolerance. Algal Research, 33, 256-265. https://doi.org/10.1016/j.algal.2018.05.021

Do, T.-T., Ong, B.-N., Nguyen Tran, M.-L., Nguyen, D., Melkonian, M., y Tran, H.-D. (2019). Biomass and astaxanthin productivities of Haematococcus pluvialis in an angled twin-layer porous substrate photobioreactor: Effect of inoculum density and storage time. Biology, 8(3), 68. https://doi.org/10.3390/biology8030068

Erturk, B. (2019). Sodium bicarbonate amendment for enhanced astaxanthin production from Haematococcus pluvialis [Disertación doctoral]. Montana: Montana State University-Bozeman, College of Engineering.

Gajardo Solari, S., Benites Vílchez, J., López Vivar, J., Burgos Hermosilla, N., Caro Galán, C. y Rojas Arredondo, M. (2011). Astaxantina: antioxidante de origen natural con variadas aplicaciones en cosmética. Biofarbo, 19, 6.

Galarza, B., Vega, A., Villóna, J., y Henríquez, V. (2019). Deesterification of astaxanthin and intermediate esters from Haematococcus pluvialis subjected to stress. Biotechnology Reports, 23, e00351. https://doi.org/10.1016/j.btre.2019.e00351

García-Malea, M. D. C., Brindley, C., Del Rio, E., Acién, F. G., Fernández, J. M., y Molina, E. (2005). Modelling of growth and accumulation of carotenoids in Haematococcus pluvialis as a function of irradiance and nutrients supply. Biochemical Engineering Journal, 26(2-3), 107-114. https://doi.org/10.1016/j.bej.2005.04.007 
Garre Pérez, A., Egea Larrosa, J. A., y Fernández Escámez, P. S. (2016). Modelos matemáticos para la descripción del crecimiento de microorganismos patógenos en alimentos. Anuario de Jóvenes Investigadores, 9, 160-163.

Gómez, L., Orozco, M. I., Quiroga, C., Díaz, J. C., Huérfano, J., Díaz, L. E., y Camacho, J. E. (2019). Producción de astaxantina y expresión de genes en Haematococcus pluvialis (Chlorophyceae, Volvocales) bajo condiciones de estrés por deficiencia de nitrógeno y alta irradiancia. Mutis, 9(2), 7-24.

Hernández Morales, K. J., Pérez Morales, M. E., Jáuregui Romo, C., Alcántara Jurado, L. A., y Hurtado Ayala, L. A. (2015). Condiciones de producción de astaxantina por Haematococcus pluvialis: Revisión bibliográfica 2003-2013. Revista Mexicana de Ciencias Farmacéuticas, 46(1), 7-16.

Hong, M. E., Choi, Y. Y., y Sim, S. J. (2016). Effect of red cyst cell inoculation and iron (II) supplementation on autotrophic astaxanthin production by Haematococcus pluvialis under outdoor summer conditions. Journal of Biotechnology, 218, 25-33. https://doi.org/10.1016/j.jbiotec.2015.11.019

Hu, J., Nagarajan, D., Zhang, Q., Chang, J. S., y Lee, D. J. (2018). Heterotrophic cultivation of microalgae for pigment production: A review. Biotechnology Advances, 36(1), 54-67. https://doi.org/10.1016/j.biotechadv.2017.09.009

Issarapayup, K., Powtongsook, S., y Pavasant, P. (2011). Economical review of Haematococcus pluvialis culture in flat-panel airlift photobioreactors. Aquacultural Engineering, 44(3), 65-71. https://doi.org/10.1016/j.aquaeng.2011.03.002

Khandual, S. (2019). Microbial source of astaxanthin: Its use as a functional food and therapeutic agent. International Journal of Biotechnology and Bioengineering, 5(6), 110-118. https://doi.org/10.1016/j.aquaeng.2011.03.002

Kiki, C., Rashid, A., Wang, Y., Li, Y., Zeng, Q., Yu, C.-P., y Sun, Q. (2019). Dissipation of antibiotics by microalgae: Kinetics, identification of transformation products and pathways. Journal of Hazardous Materials, 121985. https://doi.org/10.1016/j.jhazmat.2019.121985

Li, F., Cai, M., Lin, M., Huang, X., Wang, J., Ke, H., y An, Y. (2019). Differences between motile and nonmotile cells of Haematococcus pluvialis in the production of astaxanthin at different light intensities. Marine Drugs, 17(1), 39. https://doi.org/10.3390/md17010039

Li, X., Wang, X., Duan, C., Yi, S., Gao, Z., Xiao, C., y Li, J. (2020). Biotechnological production of astaxanthin from the microalga Haematococcus pluvialis. Biotechnology Advances, 107602. https://doi.org/10.1016/j.biotechadv.2020.107602

Liu, Y.-H., Alimujiang, A., Wang, X., Luo, S.-W., Balamurugan, S., Yang, W.D., y Li, H.-Y. (2019). Ethanol induced jasmonate pathway promotes astaxanthin hyperaccumulation in Haematococcus pluvialis. Bioresource Technology, 289, 121720. https://doi.org/10.1016/j.biortech.2019.12172

Liyanaarachchi, V. C., Nishshanka, G. K. S. H., Premaratne, R. G. M. M., Ariyadasa, T. U., Nimarshana, P. H. V., y Malik, A. (2020). Astaxanthin accumulation in the green microalga Haematococcus pluvialis: Effect of initial phosphate concentration and stepwise/continuous light stress. Biotechnology Reports, e00538. https://doi.org/10.1016/j.btre.2020.e00538 
Lobatón Garcia, H. F., Schwerna, P., y Buchholz, R. (2017). Coproducción de ficocianina y exopolisacáridos en el cultivo de Arthrospira platensis. Idesia (Arica), 35(2), 79-86. https://doi.org/10.4067/S0718-34292017005000028

Longhi, D. A., Dalcanton, F., Aragão, G. M. F. D., Carciofi, B. A. M., y Laurindo, J. B. (2017). Microbial growth models: A general mathematical approach to obtain $\mu$ max and $\lambda$ parameters from sigmoidal empirical primary models. Brazilian Journal of Chemical Engineering, 34, 369-375. https://doi.org/10.1590/01046632.20170342s20150533

Machado Jr, F. R. S., Reis, D. F., Boschetto, D. L., Burkert, J. F. M., Ferreira, S. R. S., Oliveira, J. V., y Burkert, C. A. V. (2014). Encapsulation of astaxanthin from Haematococcus pluvialis in PHBV by means of SEDS technique using supercritical $\mathrm{CO}_{2}$. Industrial Crops and Products, 54, 17-21. https://doi.org/10.1016/j.indcrop.2014.01.007

Mazumdar, N., Novis, P.M., Visnovsky, G., y Gostomski, P. (2019). Effect of culturing parameters on the vegetative growth of Haematococcus alpinus (strain LCR-CC-261f) and modeling of its growth kinetics. Journal of Phycology, 550(5), 1071-1081. https://doi.org/10.1111/jpy.12889

Miranda, A. M., Ossa, E. A., Vargas, G. J., y Sáez, A. A. (2019). Efecto de las bajas concentraciones de nitratos y fosfatos sobre la acumulación de astaxantina en Haematococcus pluvialis UTEX 2505. 2019. Información Tecnológica, 30(1), 2332. http://dx.doi.org/10.4067/S0718-07642019000100023

Montiel Oviedo, J. (2020). Efecto del nitrato en el crecimiento y producción de astaxantina en la microalga Haematococcus pluvialis (Chlorophyta: Chlamydomonadales) cultivada en condiciones de laboratorio. Montería: Universidad de Córdoba (Colombia).

Niño Castillo, C., Rodríguez Rivera, F., Díaz, L., y Lancheros Díaz, A. (2017). Evaluación de las condiciones de crecimiento celular para la producción de astaxantina a partir de la microalga Haematococcus pluvialis. Revista NOVA, 15(28), 19-31. https://doi.org/10.22490/24629448.2073

Onorato, C. y Rösch, C. (2020). Comparative evaluation of the life cycle of astaxanthin production with Haematococcus pluvialis in different photobioreactor technologies. Algal Research, 102005. https://doi.org/10.1016/j.algal.2020.102005

Orlandoni, G., y Josefa Ramoni J. (2017). Modelos de crecimiento en microbiología predictiva (ecología microbiana cuantitativa). Trabajo metodológico. Estimación de modelos y simulación mediante dinámica de sistemas. Medellín, Antioquia, Colombia.

Ortega Quintana, F. A., Álvarez, H., y Botero Castro, H. A. (2017). Facing bioprocess modeling: a review of the methodologies of modeling. Revista ION, 30(1), 73-90. https://doi.org/10.18273/revion.v30n1-2017006

Ortiz-Moreno, M. L., Cárdenas-Poblador, J., Agredo, J., y Solarte-Murillo, L. V. (2020). Modeling the effects of light wavelength on the growth of Nostoc ellipsosporum. Universitas Scientiarum, 25(1), 113-148. https://doi: 10.11144/Javeriana.SC25-1.mteo

Park J. Yao J. Soo Kim H. Young K., y Choic Y. (2020). Mechanical stress induced astaxanthin accumulation of H. pluvialis on a chip. 2020. Lab on a Chip. Número 3. https://doi.org/10.1039/C9LC01030K 
Ramírez D.M, (2013). Evaluación del crecimiento y producción de astaxantina por Haematococcus pluvialis en un fotobiorreactor tipo airlift. [Tesis de maestría]. Bogotá: Universidad Nacional de Colombia.

Rammunia, M. N., Ariyadasaa, T. U., Nimarshana, P. H. V., y Attalageb, R. A. (2019). Comparative assessment on the extraction of carotenoids from microalgal sources: Astaxanthin from H. pluvialis and $\beta$-carotene from D. salina. Food Chemistry, 277(30), 128-134. https://doi.org/10.1016/j.foodchem.2018.10.066

Saadat, N. P., Nies, T., Rousset, Y., y Ebenhöh, O. (2020). Thermodynamic limits and optimality of microbial growth. Entropy, 22(3), 277. https://doi.org/10.3390/e22030277

Sánchez-Sendra, Á. P. (2019). Efectos del carotenoide astaxantina en la salud humana, según la ciencia. RCA Grupo Editor.

Sancho Mamani, R. F. (2015). Ajuste de modelos matemáticos de crecimiento de bacterias lácticas en queso tipo paria en condiciones isotérmicas y no isotérmicas [tesis de pregrado]. Puno: Universidad Nacional del Altiplano.

Sanzo, G., Mehariya, S., Martino, M., Larocca, V., Casella, P., Chianese, S., Musmarra, D., Balducchi, R., y Molino, A. (2018). Supercritical carbon dioxide extraction of astaxanthin, lutein, and fatty acids from Haematococcus pluvialis microalgae. Marine Drugs, 16(9), 334. https://doi.org/10.3390/md16090334

Shah, M. M. R., Liang, Y., Cheng, J. J., y Daroch, M. (2016). Astaxanthinproducing green microalga Haematococcus pluvialis: From single cell to high value commercial products. Frontiers in Plant Science, 7, 531. https://doi.org/10.3389/fpls.2016.00531

Sheng, B., Fan, F., Huang, J., Bai, W., Wang, J., Li, S., y Li, Y. (2018). Investigation on models for light distribution of Haematococcus pluvialis during astaxanthin accumulation stage with an application case. Algal Research, 33, 182-189. https://doi.org/10.1016/j.algal.2018.05.011

Shoener, B. D., Schramm, S. M., Béline, F., Bernard, O., Martínez, C., Plósz, B. G., ... y Guest, J. S. (2019). Microalgae and cyanobacteria modeling in water resource recovery facilities: A critical review. Water research X, 2, 100024. https://doi.org/10.1016/j.wroa.2018.100024 Saddle River.

Shuler, M. L., y Kargi, F. (2002). Bioprocess engineering (p. 65). eUpper

Sipaúba-Tavares, L. H., Millan, R. N., y Berchielli-Morais, F. A. (2013). Effects of some parameters in upscale culture of Haematococcus pluvialis Flotow. Brazilian Journal of Biology, 73(3), 585-591. https://doi.org/10.1590/S151969842013000300016

Telli, M., y Şahin, G. (2020). Effects of gradual and sudden changes of salinity and light supply for astaxanthin production in Haematococcus pluvialis (Chlorophyceae). Fundamental and Applied Limnology, 194(1), 11-17. https://doi.org/10.1127/fal/2020/1300

Tijani, H., Yuzir, A., Dagang, W. R. Z. W., Zamyadi, A., y Abdullah, N. (2018). Multi-parametric modelling and kinetic sensitivity of microalgal cells. Algal Research, 32, 259-269. https://doi.org/10.1016/j.algal.2018.04.009 
Wang, F., Gao, B., Wu, M., Huang, L., y Zhang, C. (2019). A novel strategy for the hyper-production of astaxanthin from the newly isolated microalga Haematococcus pluvialis JNU35. Algal Research, 39. https://doi.org/10.1016/j.algal.2019.101466

Wang, J., Sommerfeld. M. R, Lu. C., y Hu, Q. (2013). Combined effect of initial biomass density and nitrogen concentration on growth and astaxanthin production of Haematococcus pluvialis (Chlorophyta) in outdoor cultivation. ALGAE, 28(2), 193-202. https://doi.org/10.4490/algae.2013.28.2.193

Wen, X., Wang, Z., Ding, Y., Geng, Y., y Li, Y. (2020). Enhancing the production of astaxanthin by mixotrophic cultivation of Haematococcus pluvialis in open raceway ponds. Aquaculture International, 28, 625-638. https://doi.org/10.1007/s10499-019-00483-2

Zhang, X. W., Gong, X. D., y Chen, F. (1999). Kinetic models for astaxanthin production by high cell density mixotrophic culture of the microalga Haematococcus pluvialis. Journal of Industrial Microbiology \& Biotechnology, 23(1), 691-696. https://doi.org/10.1038/sj.jim.2900685

Zhang, Z., Baobei, W., Qiang, H., Sommerfeld, M., Yuanguang, L., y Danxiang, H. (2016). A New Paradigm for Producing Astaxanthin from the Unicellular Green Alga Haematococcus pluvialis. Biotechnology and Bioengineering, 113(10), 2088-2099. https://doi.org/10.1002/bit.25976

Zhanga J, Christiana D, Sawdon A, y Penga C. (2018). Enhanced astaxanthin accumulation in Haematococcus pluvialis using high carbon dioxide concentration and light illumination. Bioresource Technology, 256, 548-551. https://doi.org/10.1016/j.biortech.2018.02.074

Zhao, Y., Xing, H., Li, X., Geng, S., Ning, D., Ma, T., y Yu, X. (2019). Physiological and metabolomics analyses reveal the roles of fulvic acid in enhancing the production of astaxanthin and lipids in Haematococcus pluvialis under abiotic stress conditions. Journal of Agricultural and Food Chemistry, 67, 45. https://doi.org/10.1021/acs.jafc.9b04964 